\title{
Total Synthesis of Amphidinolide E
}

\author{
Porino Va and William R. Roush* \\ Departments of Chemistry and Biochemistry \\ Scripps Florida, Jupiter, FL 33458 \\ e-mail: roush@scripps.edu
}

Supporting Information:

Part I. References to Total Syntheses of Amphidinolides A, J, K, P, T, W, X and Y (page SI-2)

Part II. Summary of Attempted Esterification Reactions of Model Substrates 22-24 (page SI-3)

Part III. Experimental Procedures for Synthesis of Amphidinolide E (pages SI-4 through SI-26). 


\section{Part I. References to Total Syntheses of Amphidinolides A, J, K, P, T, W, X and Y}

Amphidinolide A: (a) Lam, H. W.; Pattenden, G., Angew. Chem., Int. Ed. Engl. 2002, 41, 508.

(b) Maleczka, R. E., Jr.; Terrell, L. R.; Geng, F.; Ward, J. S., III, Org. Lett. 2002, 4, 2841. (c) Trost, B. M.; Chisholm, J. D.; Wrobleski, S. J.; Jung, M., J. Am. Chem. Soc. 2002, 124, 12420. (d) Trost, B. M.; Harrington, P. E., J. Am. Chem. Soc. 2004, 126, 5028. (e) Trost, B. M.; Wrobleski, S. T.; Chisholm, J. D.; Harrington, P. E.; Jung, M., J. Am. Chem. Soc. 2005, 127, 13589. (f) Trost, B. M.; Harrington, P. E.; Chisholm, J. D.; Wrobleski, S. T., J. Am. Chem. Soc. 2005, $127,13598$.

Amphidinolide J: Williams, D. R.; Kissel, W. S., J. Am. Chem. Soc. 1998, 120, 11198.

Amphidinolide K: Williams, D. R.; Meyer, K. G., J. Am. Chem. Soc. 2001, 123, 765.

Amphidinolide P: (a) Williams, D. R.; Myers, B. J.; Mi, L., Org. Lett. 2000, 2, 945. (b) Trost, B. M.; Papillon, J. P. N., J. Am. Chem. Soc. 2004, 126, 13618. (c) Trost, B. M.; Papillon, J. P. N.; Nussbaumer, T., J. Am. Chem. Soc. 2005, 127, 17921.

Amphidinolide T: (a) Fürstner, A.; Aissa, C.; Riveiros, R.; Ragot, J., Angew. Chem., Int. Ed. Engl. 2002, 41, 4763. (b) Aiessa, C.; Riveiros, R.; Ragot, J.; Fürstner, A., J. Am. Chem. Soc. 2003, 125, 15512. (c) Ghosh, A. K.; Liu, C., J. Am. Chem. Soc. 2003, 125, 2374. (d) Ghosh, A. K.; Liu, C., Strategies Tactics Org. Synth. 2004, 5, 255. (e) Colby, E. A.; O'Brien, K. C.; Jamison, T. F., J. Am. Chem. Soc. 2004, 126, 998. (f) Colby, E. A.; O'Brien, K. C.; Jamison, T. F., J. Am. Chem. Soc. 2005, 127, 4297. (g) O'Brien, K. C.; Colby, E. A.; Jamison, T. F., Tetrahedron 2005, 61, 6243. (h) Deng, L.-S.; Huang, X.-P.; Zhao, G., J. Org. Chem. 2006, 71, 4625.

Amphidinolide W: (a) Ghosh, A. K.; Gong, G., J. Am. Chem. Soc. 2004, 126, 3704. (b) Ghosh, A. K.; Gong, G., J. Org. Chem. 2006, 71, 1085.

Amphidinolide X: Lepage, O.; Kattnig, E.; Fürstner, A., J. Am. Chem. Soc. 2004, 126, 15970.

Amphidinolide Y: Fürstner, A.; Kattnig, E.; Lepage, O., J. Am. Chem. Soc. 2006, 128, 9194. 


\section{Part II.}

Table 1. Summary of Attempted Esterification Reactions of Model Substrates 22-24
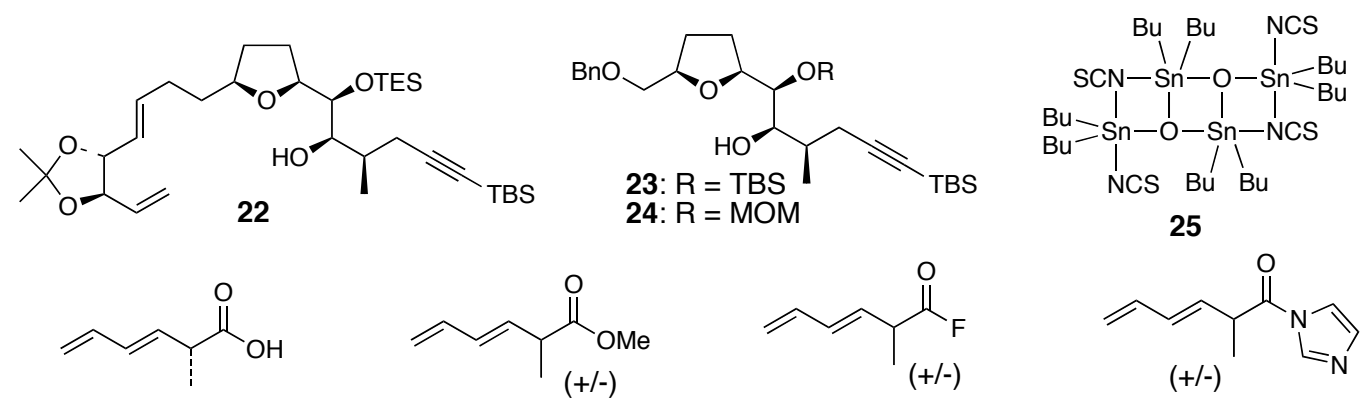

25

26

27

28

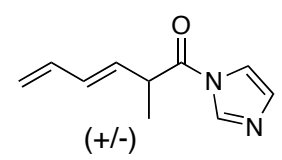

29

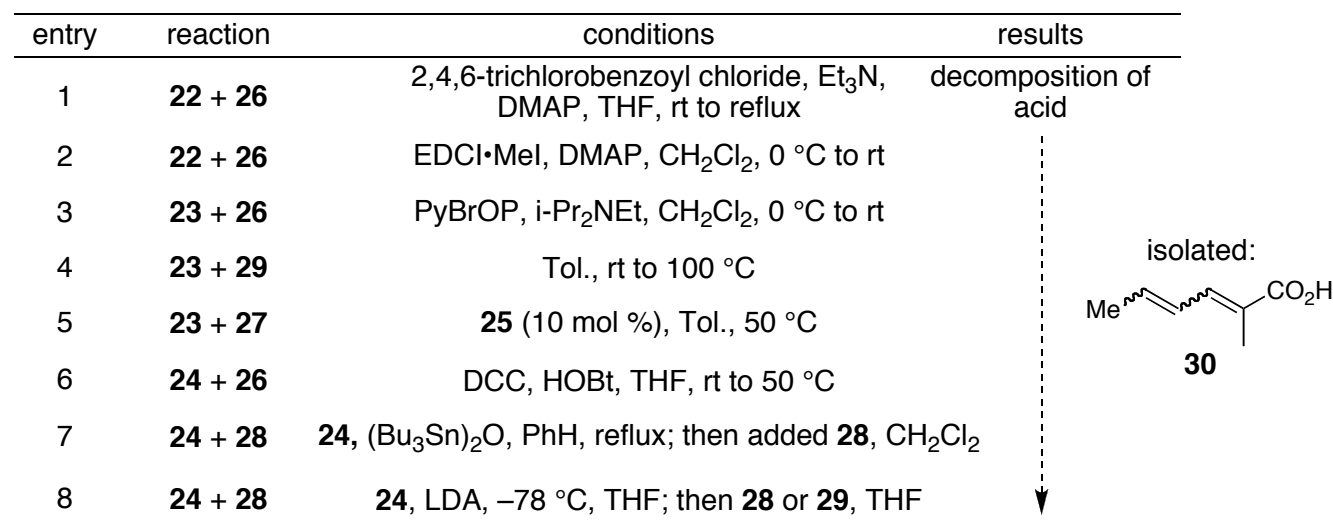

Many conditions were screened to esterify alcohol 22, or alcohols 23 and $\mathbf{2 4}$ (truncated analogs of alcohol 22) with acid $\mathbf{2 6}$ or $\mathbf{2 7}, \mathbf{2 8}$, and $\mathbf{2 9}$ (Table 1). No more than trace amounts of the corresponding ester could be isolated from all of the reactions in Table 1. Some of the conditions that failed were: the modified Yamaguchi conditions (entry 1), mild peptide coupling conditions (entries 2, 3 and 6), use of Otera's transesterification catalyst $\mathbf{2 5}^{\mathbf{1 - 3}}$ (entry 5), attempted coupling of the tributyltin ether of $\mathbf{2 4}$ with the acyl fluoride $\mathbf{2 8}$ (entry 7), and generation of the lithium alkoxide of $\mathbf{2 4}$ followed by treatment with acyl fluoride $\mathbf{2 8}$ (entry 8). In most cases, large quantities of the fully conjugated, diene migrated acid byproduct $\mathbf{3 0}$ were isolated. 


\section{Part III. Experimental Procedures for Total Synthesis of Amphidinolide E}

General Experimental Details. All reaction solvents were purified before use. Tetrahydrofuran, dichloromethane, diethyl ether, and toluene were purified by passing through a solvent column composed of activated A-1 alumina. Unless indicated otherwise, all reactions were conducted under an atmosphere of argon using flame-dried or oven-dried $\left(170{ }^{\circ} \mathrm{C}\right)$ glassware. Four $\AA$ molecular sieves were activated under high vacuum with heat $\left(180^{\circ} \mathrm{C}\right)$ for $12 \mathrm{~h}$ and re-activated by thorough flamedrying immediately prior to use.

Proton nuclear magnetic resonance $\left({ }^{1} \mathrm{H}\right.$ NMR) spectra were recorded on commercial instruments at 400 or $500 \mathrm{MHz}$. Carbon-13 nuclear magnetic resonance $\left({ }^{13} \mathrm{C} \mathrm{NMR}\right)$ spectra were recorded at 100 and $125 \mathrm{MHz}$, respectively. The proton signal for residual non-deuterated solvent $\left(\square 7.26\right.$ for $\left.\mathrm{CHCl}_{3}\right)$ was used as an internal reference for ${ }^{1} \mathrm{H}$ NMR spectra. For ${ }^{13} \mathrm{C}$ NMR spectra, chemical shifts are reported relative to the 777.2 resonance of $\mathrm{CHCl}_{3}$. Coupling constants are reported in $\mathrm{Hz}$. Infrared (IR) spectra were recorded as films on a Perkin-Elmer Spectrum One FTIR. Opitcal rotations were measured on a Rudolph Autopol IV polarimeter using a quartz cell with $1 \mathrm{~mL}$ capacity and a $10 \mathrm{~cm}$ path length. Mass spectra were recorded on a ZVG 70-250-S spectrometer manufactured by Micromass Corp. (Manchester, UK).

Analytical thin layer chromatography (TLC) was performed on Kieselgel $60 \mathrm{~F}_{254}$ glass plates precoated with a $0.25 \mathrm{~mm}$ thickness of silica gel. The TLC plates were visualized with UV light and/or by staining with Hanessian solution (ceric sulfate and ammonium molybdate in aqueous sulfuric acid). Column chromatography was generally performed using Kieselgel 60 (230-400 mesh) silica gel, typically using a 50-100:1 weight ratio of silica gel to crude product.

HPLC purifications were performed by using a HPLC system composed of two Varian Prostar pumps (model 210) connected to normal phase columns. Samples were loaded into the system with a 2 mL Rheodyne 7125 injector and were detected using a Varian Prostar UV and a Varian RI dectector.

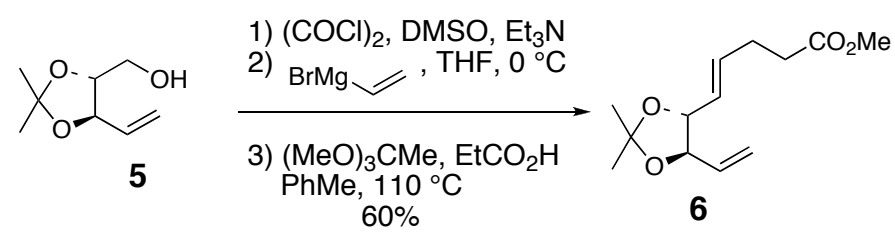

(E)-5-((4R,5R)-2,2-Dimethyl-5-vinyl-[1,3]dioxolan-4-yl)-pent-4-enoic acid methyl ester (6) To a $-78{ }^{\circ} \mathrm{C}$ solution of $(\mathrm{COCl})_{2}(3.45 \mathrm{~mL}, 39.4 \mathrm{mmol})$ in $\mathrm{CH}_{2} \mathrm{Cl}_{2}(80 \mathrm{~mL})$ was added DMSO $(3.50 \mathrm{~mL}$, $49.2 \mathrm{mmol})$ in $\mathrm{CH}_{2} \mathrm{Cl}_{2}(10 \mathrm{~mL})$. The reaction was stirred at $-78{ }^{\circ} \mathrm{C}$ for $15 \mathrm{~min}$, then alcohol $\mathbf{5}^{4}(3.12 \mathrm{~g}$, $19.7 \mathrm{mmol})$ in $\mathrm{CH}_{2} \mathrm{Cl}_{2}(10 \mathrm{~mL})$ was added. The reaction was stirred for 20 minutes at $-78{ }^{\circ} \mathrm{C}$ followed by the addition of triethylamine $(16.4 \mathrm{~mL}, 118 \mathrm{mmol})$. The mixture was allowed to warm to $0{ }^{\circ} \mathrm{C}$. After 30 
minutes, the reaction was diluted with $\mathrm{Et}_{2} \mathrm{O}(300 \mathrm{~mL})$, upon which a white precipitate forms (triethylamine hydrochloride). The slurry was filtered through a 1 inch pad of Celite and concentrated to afford the aldehyde, a yellow oil, which was immediately used in the next reaction.

To a $0{ }^{\circ} \mathrm{C}$ solution of the crude aldehyde in THF $(60 \mathrm{~mL})$ was added vinylmagnesium bromide (60 $\mathrm{mL}$ of a 1.0M THF solution, $60 \mathrm{mmol}$ ). The reaction was stirred for $2.5 \mathrm{~h}$, and then quenched with saturated aqueous $\mathrm{NaHCO}_{3}(50 \mathrm{~mL})$ and extract with $\mathrm{Et}_{2} \mathrm{O}(20 \mathrm{~mL}$ x 3). The organic phase was washed with brine $(50 \mathrm{~mL})$, dried over anhydrous $\mathrm{MgSO}_{4}$, filtered, and concentrated to afford a mixture of diastereomeric allylic alcohols as a yellow oil. This oil was used immediately in the next reaction.

To the mixture of diastereomeric allylic alcohols, from the preceeding step, in toluene $(66 \mathrm{~mL})$ was added trimethyl orthoacetate $(12.5 \mathrm{~mL}, 98.5 \mathrm{mmol})$ and propionoic acid $(0.3 \mathrm{~mL}, 3.94 \mathrm{mmol})$. The reaction was fitted with a condenser and placed in a $110{ }^{\circ} \mathrm{C}$ oil bath for $18 \mathrm{~h}$. The solution was then quenched with $3 \mathrm{~mL}$ of triethylamine and concentrated. The crude product was purified by flash column chromatography to yield methyl ester $6(2.83 \mathrm{~g}, 60 \%$ over 3 steps $)$ as a colorless oil: $[\square]^{25}{ }_{\mathrm{D}}=-132^{\circ}(\mathrm{c}$ 0.99, $\left.\mathrm{CHCl}_{3}\right) ;{ }^{1} \mathrm{H}$ NMR $\left(400 \mathrm{MHz}, \mathrm{CDCl}_{3}\right) \square 5.74-5.83(\mathrm{~m}, 2 \mathrm{H}), 5.48(\mathrm{dd}, J=6.4,15.2 \mathrm{~Hz}, 1 \mathrm{H}), 5.33(\mathrm{~d}, J$ $=17.2 \mathrm{~Hz}, 1 \mathrm{H}), 5.24(\mathrm{~d}, J=10.4 \mathrm{~Hz}, 1 \mathrm{H}), 4.04(\operatorname{app~q}, J=6.8 \mathrm{~Hz}, 2 \mathrm{H}), 3.67(\mathrm{~s}, 3 \mathrm{H}), 2.36-2.44(\mathrm{~m}, 4 \mathrm{H})$, $1.44(\mathrm{~s}, 3 \mathrm{H}), 1.43(\mathrm{~s}, 3 \mathrm{H}) ;{ }^{13} \mathrm{C} \mathrm{NMR}\left(100 \mathrm{MHz}, \mathrm{CDCl}_{3}\right) \square 172.8,134.0,133.7,126.9,118.3,108.7,82.0$, 81.6, 51.3, 33.1, 27.3, 26.8, 26.7; IR (neat) 2987, 2874, 1740, 1437, $1371 \mathrm{~cm}^{-1}$; HRMS (ES+) $\mathrm{m} / z$ for $\mathrm{C}_{12} \mathrm{H}_{18} \mathrm{O}_{3} \mathrm{Na}[\mathrm{M}+\mathrm{Na}]^{+}$calcd 263.1259, found 263.1255.

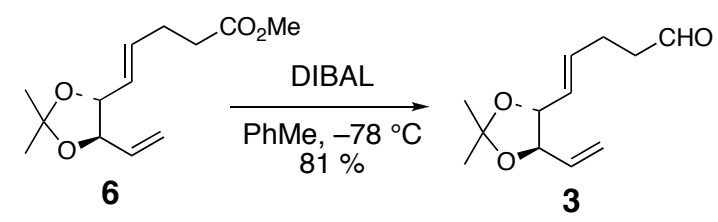

(E)-5-((4R,5R)-2,2-Dimethyl-5-vinyl-[1,3]dioxolan-4-yl)-pent-4-enal (3) To a $-78{ }^{\circ} \mathrm{C}$ solution of methyl ester $6(2.25 \mathrm{~g}, 9.36 \mathrm{mmol})$ in toluene $(31 \mathrm{~mL})$ was added DIBAL $(9.36 \mathrm{~mL}$ of a $1.0 \mathrm{M}$ hexane solution, $9.36 \mathrm{mmol}$ ) dropwise such that the internal temperature was below $-70{ }^{\circ} \mathrm{C}$. After being stirred for $30 \mathrm{~min}$, the reaction was quenched with saturated aqueous sodium potassium tartrate (Rochelle's salt) $(40 \mathrm{~mL})$ and diluted with $\mathrm{Et}_{2} \mathrm{O}(20 \mathrm{~mL})$. The mixure was stirred at room temperature for $3 \mathrm{~h}$ and extracted with $\mathrm{Et}_{2} \mathrm{O}(20 \mathrm{~mL} \times 3)$. The organic phase was washed with brine $(50 \mathrm{~mL})$, dried over anhydrous $\mathrm{MgSO}_{4}$, filtered, and concentrated. The crude product was purified by flash column chromatography to afford aldehyde 3 (1.59 g, 81\%) as a colorless oil: $[\square]_{\mathrm{D}}^{25}=-28.7^{\circ}\left(c 1.41, \mathrm{CHCl}_{3}\right) ;{ }^{1} \mathrm{H} \mathrm{NMR}\left(400 \mathrm{MHz}, \mathrm{CDCl}_{3}\right)$ $\square 9.73$ (bs, 1H), 5.70-5.85 (m, 2H), 5.49 (bdd, $J=6.0,15.6 \mathrm{~Hz}, 1 \mathrm{H}), 5.34$ (d, $J=17.2 \mathrm{~Hz}, 1 \mathrm{H}), 5.24$ (d, $J$ $=10.4 \mathrm{~Hz}, 1 \mathrm{H}), 4.00-4.10(\mathrm{~m}, 2 \mathrm{H}), 2.52-2.60(\mathrm{~m}, 2 \mathrm{H}), 2.35-2.45(\mathrm{~m}, 2 \mathrm{H}), 1.44(\mathrm{~s}, 3 \mathrm{H}), 1.43(\mathrm{~s}, 3 \mathrm{H}) ;{ }^{13} \mathrm{C}$ NMR (100MHz, $\left.\mathrm{CDCl}_{3}\right) \square 201.3,134.1,133.8,127.2,118.8,109.0,82.2,81.8,42.8,27.0,27.0,24.7$; IR 
(neat) $3085,2987,2875,1726,1379,1371,1239 \mathrm{~cm}^{-1}$; HRMS (ES+) $m / z$ for $\mathrm{C}_{13} \mathrm{H}_{20} \mathrm{O}_{3} \mathrm{Na}[\mathrm{M}+\mathrm{Na}]^{+}$calcd 233.1154 , found 233.1245 .
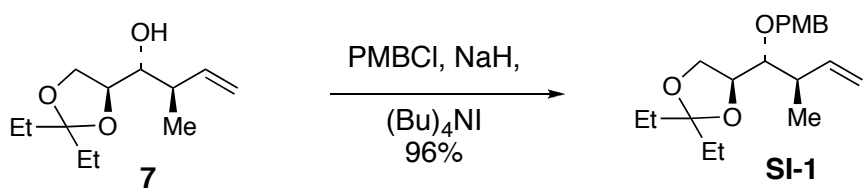

\section{(S)-2,2-Diethyl-4-[(1R,2R)-1-(4-methoxy-benzyloxy)-2-methyl-but-3-enyl]-[1,3]dioxolane}

(SI-1) To a $0{ }^{\circ} \mathrm{C}$ slurry of $\mathrm{NaH}(1.69 \mathrm{~g}, 70.6 \mathrm{mmol})$ and $\mathrm{Bu}_{4} \mathrm{NI}(1.7 \mathrm{~g}, 4.7 \mathrm{mmol})$ in THF $(157 \mathrm{~mL})$ was added homoallylic alcohol $7^{5}(10.1 \mathrm{~g}, 47.0 \mathrm{mmol})$ followed by PMBCl $(6.38 \mathrm{~mL}, 47.0 \mathrm{mmol})$. The reaction was fitted with a condenser and refluxed for $16 \mathrm{~h}$. The reaction was quenched with sat. aq. $\mathrm{NH}_{4} \mathrm{Cl}(50 \mathrm{~mL})$ and water $(50 \mathrm{~mL})$ and extracted with EtOAc $(25 \mathrm{~mL}$ x 3). The organic phase was washed with brine, dried over anhydrous $\mathrm{MgSO}_{4}$, filtered and concentrated. The crude product was purified by flash column chromatography to afford SI-1 $(15.15 \mathrm{~g}, 96 \%)$ as a colorless oil: $[\square]^{25}=-41^{\circ}(c$ 1.53, $\left.\mathrm{CHCl}_{3}\right) ;{ }^{1} \mathrm{H}$ NMR $\left(400 \mathrm{MHz}, \mathrm{CDCl}_{3}\right) \square 7.25(\mathrm{~d}, J=8.4 \mathrm{~Hz}, 2 \mathrm{H}), 6.87(\mathrm{~d}, J=8.4 \mathrm{~Hz}, 2 \mathrm{H}), 5.86$ (ddd, $J=8.0,10.4,17.2 \mathrm{~Hz}, 1 \mathrm{H}), 5.04$ (app t, $J=17.6 \mathrm{~Hz}, 2 \mathrm{H}), 4.60(\mathrm{AB}, J=10.8 \mathrm{~Hz}, 1 \mathrm{H}), 4.55(\mathrm{AB}, J$ $=11.2 \mathrm{~Hz}, 2 \mathrm{H}), 4.05-4.10(\mathrm{~m}, 1 \mathrm{H}), 4.00(\mathrm{dd}, J=6.0,7.6 \mathrm{~Hz}, 1 \mathrm{H}), 3.81(\mathrm{~s}, 3 \mathrm{H}), 3.77(\mathrm{~d}, J=7.6 \mathrm{~Hz}, 1 \mathrm{H})$, $3.52(\mathrm{dd}, J=3.6,6.0 \mathrm{~Hz}, 1 \mathrm{H}), 2.50-2.54(\mathrm{~m}, 1 \mathrm{H}), 1.57-1.70(\mathrm{~m}, 4 \mathrm{H}), 1.09(\mathrm{~d}, J=6.8 \mathrm{~Hz}, 3 \mathrm{H}), 0.89(\mathrm{dt}, J$ = 9.6, 7.6 Hz, 6H); ${ }^{13} \mathrm{C}$ NMR $\left(100 \mathrm{MHz}, \mathrm{CDCl}_{3}\right) \square 159.1,140.1,130.1,129.3,115.0,113.7,112.1,83.1$, 77.3, 74.0, 66.9, 55.2, 40.8, 29.7, 29.0, 17.0, 8.2, 8.1; IR (neat) 3073, 2972, 1613, 1514, $1249 \mathrm{~cm}^{-1}$; HRMS (ES+) $m / z$ for $\mathrm{C}_{20} \mathrm{H}_{30} \mathrm{O}_{4} \mathrm{Na}[\mathrm{M}+\mathrm{Na}]^{+}$calcd 357.2042, found 357.2044.
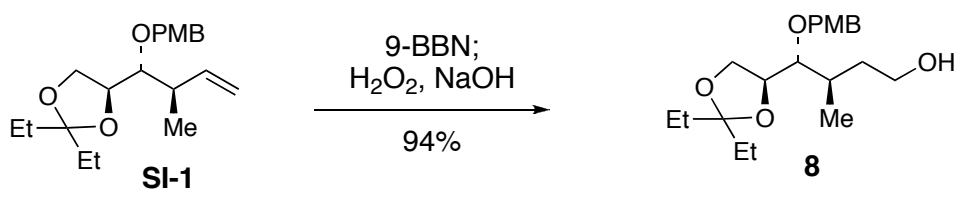

\section{(3R,4R)-4-((S)-2,2-Diethyl-[1,3] dioxolan-4-yl)-4-(4-methoxy-benzyloxy)-3-methyl-butan-1-ol}

(8) To a solution of SI-1 (15.1 g, $45.3 \mathrm{mmol})$ in THF $(181 \mathrm{~mL})$ was added 9-BBN (272 $\mathrm{mL}$ of a $0.5 \mathrm{M}$ THF solution, $136 \mathrm{mmol}$ ). The reaction was fitted with a condenser, refluxed for $3 \mathrm{~h}$, cooled to $0{ }^{\circ} \mathrm{C}$ and quenched with water $(25 \mathrm{~mL})$. The mixure was then treated with $2 \mathrm{~N} \mathrm{NaOH}$ aq. $(227 \mathrm{~mL})$ followed by $30 \%(\mathrm{w} / \mathrm{w}) \mathrm{H}_{2} \mathrm{O}_{2}(46.3 \mathrm{~mL})$ and the biphasic mixture was stirred at room temperature for $17 \mathrm{~h}$. The aqueous phase was extracted with EtOAc $(50 \mathrm{~mL}$ x 3). The organic phase was washed with brine, dried over anhydrous $\mathrm{MgSO}_{4}$, filtered and concentrated. The crude product was purified by flash column chromatography to afford $8(15.1 \mathrm{~g}, 94 \%)$ as a colorless oil: $[\square]^{25}=-27^{\circ}\left(c 0.63, \mathrm{CHCl}_{3}\right) ;{ }^{1} \mathrm{H}$ NMR $\left(500 \mathrm{MHz}, \mathrm{CDCl}_{3}\right) \square 7.24(\mathrm{~d}, J=8.5 \mathrm{~Hz}, 2 \mathrm{H}), 6.87(\mathrm{~d}, J=8.4 \mathrm{~Hz}, 2 \mathrm{H}), 4.56(\mathrm{~s}, 2 \mathrm{H}), 4.16$ (app q, $J=6.5$ $\mathrm{Hz}, 1 \mathrm{H}), 4.07$ (dd, $J=6.0,8.0 \mathrm{~Hz}, 1 \mathrm{H}), 3.80(\mathrm{~s}, 3 \mathrm{H}), 3.75$ (app t, $J=8.0 \mathrm{~Hz}, 1 \mathrm{H}), 3.70-3.76(\mathrm{~m}, 1 \mathrm{H})$, 3.60-3.64 (m, 1H), $3.46(\mathrm{dd}, J=4.5,6.0 \mathrm{~Hz}, 1 \mathrm{H}), 2.02-2.07(\mathrm{~m}, 1 \mathrm{H}), 1.95(\mathrm{dd}, J=4.5,6.0 \mathrm{~Hz}, 1 \mathrm{H})$, 
1.73-1.79 (m, 1H), 1.58-1.67 (m, 4H), $1.03(\mathrm{~d}, J=7.0 \mathrm{~Hz}, 3 \mathrm{H}), 0.89(\mathrm{dt}, J=7.0,5.5 \mathrm{~Hz}, 6 \mathrm{H}) ;{ }^{13} \mathrm{C}$ NMR $\left(125 \mathrm{MHz}, \mathrm{CDCl}_{3}\right) \square 159.2,130.3,129.3,113.7,112.6,83.3,77.3,76.3,67.7,60.5,55.2,34.9,32.1,29.7$, 29.0, 16.3, 8.2; IR (neat) 3436, 2971, 2881, 1613, 1514, $1249 \mathrm{~cm}^{-1}$; HRMS (ES+) $m / z$ for $\mathrm{C}_{20} \mathrm{H}_{32} \mathrm{O}_{5} \mathrm{Na}$ $[\mathrm{M}+\mathrm{Na}]^{+}$calcd 375.2147 , found 375.2141 .
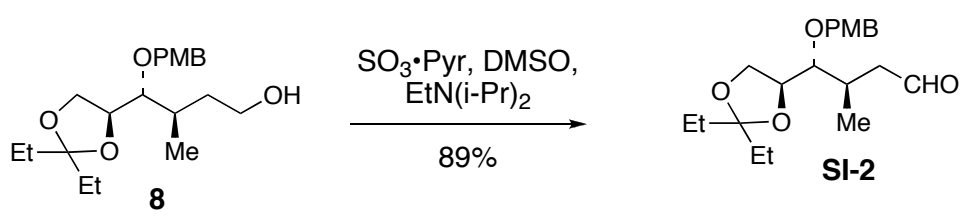

\section{(3R,4R)-4-((S)-2,2-Diethyl-[1,3] dioxolan-4-yl)-4-(4-methoxy-benzyloxy)-3-methyl-}

butyraldehyde (SI-2) To a $0{ }^{\circ} \mathrm{C}$ solution of alcohol 8 (15.0 g, $\left.42.6 \mathrm{mmol}\right)$ in $\mathrm{CH}_{2} \mathrm{Cl}_{2}(142 \mathrm{~mL})$ was added DMSO (9.1 mL, $128 \mathrm{mmol})$, i-Pr $2 \mathrm{NEt}(22.2 \mathrm{~mL}, 128 \mathrm{mmol})$ and $\mathrm{SO}_{3} \cdot \operatorname{Pyr}(20.3 \mathrm{~g}, 128 \mathrm{mmol})$. The reaction was stirred at $0{ }^{\circ} \mathrm{C}$ for $30 \mathrm{~min}$, then quenched with sat. aq. $\mathrm{Na}_{2} \mathrm{~S}_{2} \mathrm{O}_{3}(100 \mathrm{~mL})$ and extracted with $\mathrm{CH}_{2} \mathrm{Cl}_{2}(30 \mathrm{~mL} \times 3)$. The organic phase was washed with brine, dried over anhydrous $\mathrm{MgSO}_{4}$, filtered and concentrated. The crude product was purified by flash column chromatography to afford SI-2 (13.39 g, 89\%) as a colorless oil: $[\square]^{25}{ }_{\mathrm{D}}=-30^{\circ}\left(\mathrm{c} 2.2, \mathrm{CHCl}_{3}\right) ;{ }^{1} \mathrm{H}$ NMR $\left(500 \mathrm{MHz}, \mathrm{CDCl}_{3}\right) \square 9.73$ (app t, $J=2.0$ $\mathrm{Hz}, 1 \mathrm{H}), 7.23(\mathrm{~d}, J=9.0 \mathrm{~Hz}, 2 \mathrm{H}), 6.87(\mathrm{~d}, J=9.0 \mathrm{~Hz}, 2 \mathrm{H}), 4.56(\mathrm{AB}, J=11.0 \mathrm{~Hz}, 1 \mathrm{H}), 4.53(\mathrm{AB}, J=$ $11.0 \mathrm{~Hz}, 1 \mathrm{H}), 4.12(\mathrm{dd}, J=6.5,13.0 \mathrm{~Hz}, 1 \mathrm{H}), 4.06(\mathrm{dd}, J=6.5,8.0 \mathrm{~Hz}, 1 \mathrm{H}), 3.80(\mathrm{~s}, 3 \mathrm{H}), 3.73(\mathrm{t}, J=$ $8.0 \mathrm{~Hz}, 1 \mathrm{H}), 3.40(\mathrm{dd}, J=4.5,6.0 \mathrm{~Hz}, 1 \mathrm{H}), 2.65(\mathrm{ddd}, J=2.0,6.0,7.5 \mathrm{~Hz}, 1 \mathrm{H}), 2.43-2.48(\mathrm{~m}, 1 \mathrm{H}), 2.37$ $(\mathrm{ddd}, J=2.0,7.5,9.5 \mathrm{~Hz}, 1 \mathrm{H}), 1.57-1.67(\mathrm{~m}, 4 \mathrm{H}), 1.06(\mathrm{~d}, J=7.5, \mathrm{~Hz}, 3 \mathrm{H}), 0.88(\mathrm{t}, J=7.0 \mathrm{~Hz}, 6 \mathrm{H}) ;{ }^{13} \mathrm{C}$ NMR $\left(125 \mathrm{MHz}, \mathrm{CDCl}_{3}\right) \square 202.2,159.2,130.2,129.4,113.7,113.0,82.2,76.1,73.3,67.6,55.2,47.1$, 30.3, 29.7, 28.9, 16.5, 8.2, 8.2; IR (neat) 2971, 2934, 2724, 2721, 1724, 1514, $1249 \mathrm{~cm}^{-1}$; HRMS (ES+) $m / z$ for $\mathrm{C}_{20} \mathrm{H}_{30} \mathrm{O}_{5} \mathrm{Na}[\mathrm{M}+\mathrm{Na}]^{+}$calcd 373.1991, found 373.1984.
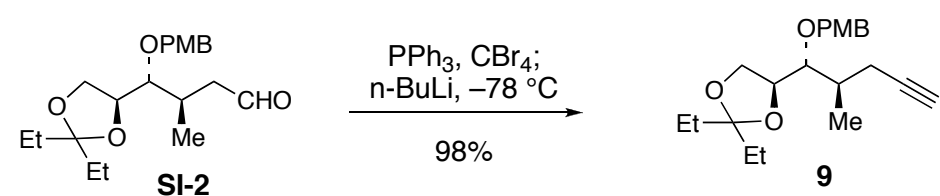

\section{(S)-2,2-Diethyl-4-[(1R,2R)-1-(4-methoxy-benzyloxy)-2-methyl-pent-4-ynyl]-[1,3]dioxolane}

(9) To a $0{ }^{\circ} \mathrm{C}$ solution of $\mathrm{PPh}_{3}(24.9 \mathrm{~g}, 94.87 \mathrm{mmol})$ in $\mathrm{CH}_{2} \mathrm{Cl}_{2}(182 \mathrm{~mL})$ was added $\mathrm{CBr}_{4}(15.7 \mathrm{~g}, 47.4$ mmol). The reaction was warmed to room temperture for $30 \mathrm{~min}$ and then cooled back to $0{ }^{\circ} \mathrm{C}$. To this mixture was added aldehyde SI-2 $(12.8 \mathrm{~g}, 36.5 \mathrm{mmol})$ in $\mathrm{CH}_{2} \mathrm{Cl}_{2}(5 \mathrm{~mL})$. The reaction was stirred for 30 min and then diluted with hexane $(400 \mathrm{~mL})$, upon which a white precipitate formed $\left(\mathrm{Ph}_{3} \mathrm{P}=\mathrm{O}\right)$. The slurry was filtered through Celite and concentrated. The residue was dissolve in hexane $(300 \mathrm{~mL})$ to precipitate more $\mathrm{Ph}_{3} \mathrm{P}=\mathrm{O}$. The slurry was filtered through Celite and again concentrated. The residual oil was dissolved in THF $(100 \mathrm{~mL})$, cooled to $-78{ }^{\circ} \mathrm{C}$ and treated with $\mathrm{n}$-BuLi $(32.4 \mathrm{~mL}$ of $2.29 \mathrm{M}$ hexane solution, $74.3 \mathrm{mmol})$. The reaction was stirred for $1 \mathrm{~h}$ and then quenched with sat. aq. $\mathrm{NH}_{4} \mathrm{Cl}(100 \mathrm{~mL})$ 
and extracted with EtOAc $(50 \mathrm{~mL} \times 3)$. The organic phase was washed with brine, dried over anhydrous $\mathrm{MgSO}_{4}$, filtered and concentrated. Purification of the crude product by flash column chromatography afforded $9(11.0 \mathrm{~g}, 98 \%)$ as a colorless oil: $[\square]^{25}{ }_{\mathrm{D}}=-7.6^{\circ}\left(c \mathrm{c} 0.89, \mathrm{CHCl}_{3}\right) ;{ }^{1} \mathrm{H} \mathrm{NMR}\left(400 \mathrm{MHz}, \mathrm{CDCl}_{3}\right) \square$ $7.25(\mathrm{~d}, J=8.8 \mathrm{~Hz}, 2 \mathrm{H}), 6.87(\mathrm{~d}, J=8.8 \mathrm{~Hz}, 2 \mathrm{H}), 4.62(\mathrm{AB}, J=10.8 \mathrm{~Hz}, 1 \mathrm{H}), 4.54(\mathrm{AB}, J=11.2 \mathrm{~Hz}$, $1 \mathrm{H}), 4.17$ (dt, $J=6.0,8.0 \mathrm{~Hz}, 1 \mathrm{H}), 4.03$ (dd, $J=6.0,8.0 \mathrm{~Hz}, 1 \mathrm{H}), 3.80$ (s, 3H), 3.77 (t, $J=8.0 \mathrm{~Hz}, 1 \mathrm{H})$, $3.57(\mathrm{t}, J=6.0 \mathrm{~Hz}, 1 \mathrm{H}), 2.27-2.39(\mathrm{~m}, 2 \mathrm{H}), 1.98(\operatorname{app~t}, J=3.2 \mathrm{~Hz}, 1 \mathrm{H}), 1.91-1.98(\mathrm{~m}, 1 \mathrm{H}), 1.56-1.71$ $(\mathrm{m}, 4 \mathrm{H}), 1.10(\mathrm{~d}, J=7.2 \mathrm{~Hz}, 3 \mathrm{H}), 0.90$ (app q, $J=7.6 \mathrm{~Hz}, 6 \mathrm{H}) ;{ }^{13} \mathrm{C}$ NMR $\left(100 \mathrm{MHz}, \mathrm{CDCl}_{3}\right) \square 159.2$, 130.5, 129.4, 113.7, 112.8, 83.2, 81.2, 76.5, 73.7, 69.4, 67.0, 55.2, 34.9, 29.7, 29.0, 22.1, 15.7, 8.2, 8.1; IR (neat) $3295,2971,1613,1514 \mathrm{~cm}^{-1}$; HRMS (ES+) $\mathrm{m} / z$ for $\mathrm{C}_{21} \mathrm{H}_{30} \mathrm{O}_{4} \mathrm{Na}[\mathrm{M}+\mathrm{Na}]^{+}$calcd 369.2042 , found 369.2037 .

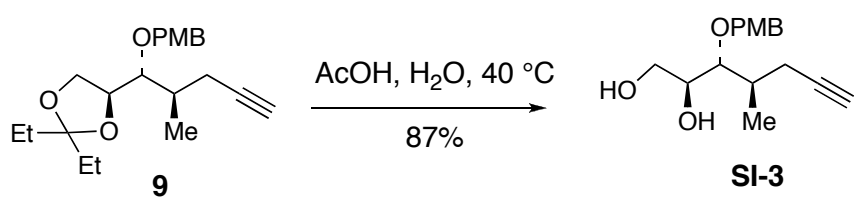

(2S,3R,4R)-3-(4-Methoxy-benzyloxy)-4-methyl-hept-6-yne-1,2-diol (SI-3) To alkyne 9 (4.84 g, $14.0 \mathrm{mmol})$ was added a 4:1 mixture of $\mathrm{AcOH}$ and water $(47 \mathrm{~mL})$. The reaction mixture was heated to $40{ }^{\circ} \mathrm{C}$ for $6 \mathrm{~h}$ and then was diluted with $50 \mathrm{~mL}$ of EtOAc. Solid $\mathrm{NaHCO}_{3}(20 \mathrm{~g})$ was slowly added portionwise and then the mixture was extracted with EtOAc $(25 \mathrm{~mL}$ x 3). The organic phase was washed with brine, dried over anhydrous $\mathrm{MgSO}_{4}$, filtered and concentrated. The crude product was purified by flash column chromatography to afford diol SI-3 $(3.39 \mathrm{~g}, 87 \%)$ as a colorless oil: $[\square]_{\mathrm{D}}^{25}=+13.6^{\circ}(c 0.59$, $\left.\mathrm{CHCl}_{3}\right) ;{ }^{1} \mathrm{H} \mathrm{NMR}\left(400 \mathrm{MHz}, \mathrm{CDCl}_{3}\right) \square 7.27(\mathrm{~d}, J=8.8 \mathrm{~Hz}, 2 \mathrm{H}), 6.89(\mathrm{~d}, J=8.8 \mathrm{~Hz}, 2 \mathrm{H}), 4.64(\mathrm{AB}, J=$ $11.2 \mathrm{~Hz}, 1 \mathrm{H}), 4.61(\mathrm{AB}, J=11.2 \mathrm{~Hz}, 1 \mathrm{H}), 3.80(\mathrm{~s}, 3 \mathrm{H}), 3.69-3.84(\mathrm{~m}, 3 \mathrm{H}), 3.58$ (dd, $J=4.4,7.2 \mathrm{~Hz}$, $1 \mathrm{H}), 2.33-2.46(\mathrm{~m}, 3 \mathrm{H}), 2.18(\mathrm{dd}, J=4.0,8.0 \mathrm{~Hz}, 1 \mathrm{H}), 2.03(\mathrm{t}, J=2.4 \mathrm{~Hz}, 1 \mathrm{H}), 1.96-2.02(\mathrm{~m}, 1 \mathrm{H}), 7.27$ $(\mathrm{d}, J=8.8 \mathrm{~Hz}, 2 \mathrm{H}), 1.08(\mathrm{~d}, J=6.8 \mathrm{~Hz}, 3 \mathrm{H}) ;{ }^{13} \mathrm{C} \mathrm{NMR}\left(100 \mathrm{MHz}, \mathrm{CDCl}_{3}\right) \square 159.4,130.3,129.6,113.9$, 83.8, 83.0, 74.8, 71.5, 69.9, 63.3, 55.3, 34.4, 21.9, 16.3; IR (neat) 3413, 3306, 2936, 1612, 1515, $1249 \mathrm{~cm}^{-}$ ${ }^{1}$; HRMS (ES+) $m / z$ for $\mathrm{C}_{16} \mathrm{H}_{22} \mathrm{O}_{4} \mathrm{Na}[\mathrm{M}+\mathrm{Na}]^{+}$calcd 301.1416, found 301.1416.

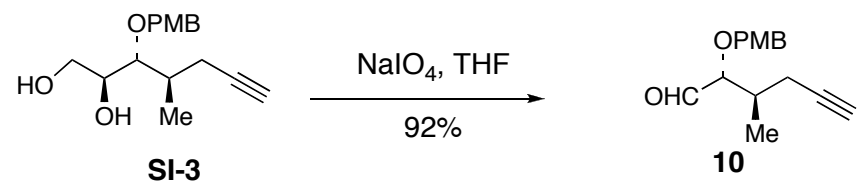

(2R,3R)-2-(4-Methoxy-benzyloxy)-3-methyl-hex-5-ynal (10) To a $0{ }^{\circ} \mathrm{C}$ solution of SI-3 (3.39 $\mathrm{g}, 12.2 \mathrm{mmol})$ in THF $(20 \mathrm{~mL})$ and $\mathrm{pH} 7$ buffer $(20 \mathrm{~mL})$ was added $\mathrm{NaIO}_{4}(3.13 \mathrm{~g}, 14.6 \mathrm{mmol})$. The reaction was stirred for $4 \mathrm{~h}$, quenched with sat. aq. $\mathrm{Na}_{2} \mathrm{~S}_{2} \mathrm{O}_{3}(25 \mathrm{~mL})$ and extracted with EtOAc $(25 \mathrm{~mL} \mathrm{x}$ 3). The organic phase was washed with brine, dried over anhydrous $\mathrm{MgSO}_{4}$, filtered and concentrated to 
afford pure $10(2.76 \mathrm{~g}, 92 \%)$ as a colorless oil: $[\square]^{25}{ }_{\mathrm{D}}=+80^{\circ}\left(c 2.26, \mathrm{CHCl}_{3}\right) ;{ }^{1} \mathrm{H} \mathrm{NMR}\left(500 \mathrm{MHz}, \mathrm{CDCl}_{3}\right)$ $\square 9.65(\operatorname{app~d}, J=3.0 \mathrm{~Hz}, 1 \mathrm{H}), 7.27(\mathrm{~d}, J=8.5 \mathrm{~Hz}, 2 \mathrm{H}), 6.89(\mathrm{~d}, J=8.5 \mathrm{~Hz}, 2 \mathrm{H}), 4.59(\mathrm{~d}, J=11.5 \mathrm{~Hz}$, $1 \mathrm{H}), 4.47(\mathrm{~d}, J=11.5 \mathrm{~Hz}, 1 \mathrm{H}), 3.81(\mathrm{~s}, 3 \mathrm{H}), 3.60(\mathrm{dd}, J=3.0,10.0 \mathrm{~Hz}, 1 \mathrm{H}), 2.34-2.36(\mathrm{~m}, 2 \mathrm{H}), 2.11$ $2.17(\mathrm{~m}, 1 \mathrm{H}), 1.98(\operatorname{app~t}, J=2.5 \mathrm{~Hz}, 1 \mathrm{H}), 1.04(\mathrm{~d}, J=7.0 \mathrm{~Hz}, 3 \mathrm{H}) ;{ }^{13} \mathrm{C} \mathrm{NMR}\left(125 \mathrm{MHz}, \mathrm{CDCl}_{3}\right)$ ○203.5, 159.5, 129.8, 129.2, 113.8, 85.6, 81.9, 72.8, 70.4, 55.2, 34.0, 21.3, 15.3; IR (neat) 3292, 2967, 2837, 1731, 1515, $1249 \mathrm{~cm}^{-1}$; HRMS (ES+) $\mathrm{m} / z$ for $\mathrm{C}_{15} \mathrm{H}_{18} \mathrm{O}_{3} \mathrm{Na}[\mathrm{M}+\mathrm{Na}]^{+}$calcd 269.1154, found 269.1147.

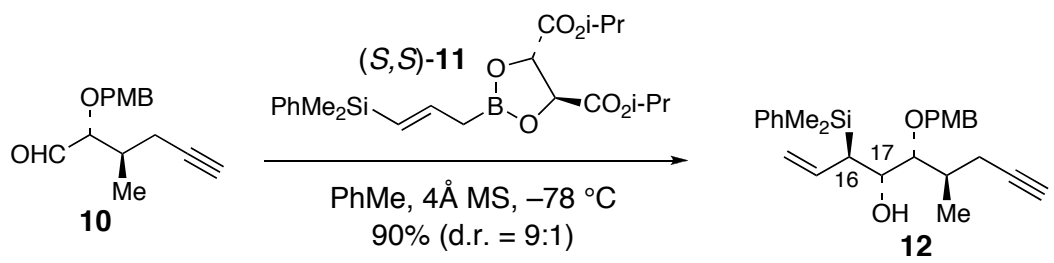

(3R,4S,5R,6R)-3-(Dimethylphenylsilanyl)-5-(4-methoxy-benzyloxy)-6-methyl-non-1-en-8-

yn-4-ol (12) To a $-78{ }^{\circ} \mathrm{C}$ slurry of aldehyde 10 (5.95 g, $\left.24.2 \mathrm{mmol}\right)$ and $4 \AA$ mol. sieves $(4.8 \mathrm{~g})$ in toluene $(20 \mathrm{~mL})$ was added $(S, S)-\mathbf{1 1}^{6}(61 \mathrm{~mL}$ of a $1.0 \mathrm{M}$ solution in toluene, $60.4 \mathrm{mmol})$. The reaction was stirred at $-78{ }^{\circ} \mathrm{C}$ for $18 \mathrm{~h}$ and then quenched with $2 \mathrm{~N} \mathrm{NaOH}$ aq. $(100 \mathrm{~mL})$. The biphasic mixture was filtered through Celite and extracted with EtOAc $(30 \mathrm{~mL}$ x 3). The organic phase was washed with brine, dried over anhydrous $\mathrm{MgSO}_{4}$, filtered and concentrated. The crude product was purified by flash column chromatography to afford $12(9.19 \mathrm{~g}, 90 \%)$ as a colorless oil: $[\square]_{\mathrm{D}}^{25}=-6^{\circ}\left(\mathrm{c} 2.48, \mathrm{CHCl}_{3}\right) ;{ }^{1} \mathrm{H} \mathrm{NMR}$ $\left(400 \mathrm{MHz}, \mathrm{CDCl}_{3}\right) \square 7.55-7.57(\mathrm{~m}, 2 \mathrm{H}), 7.34-7.36(\mathrm{~m}, 3 \mathrm{H}), 7.25(\mathrm{~d}, J=8.8 \mathrm{~Hz}, 2 \mathrm{H}), 6.88(\mathrm{~d}, J=8.8 \mathrm{~Hz}$, 2H), $5.98(\mathrm{dt}, J=10.4,21.5 \mathrm{~Hz}, 1 \mathrm{H}), 5.03(\mathrm{~d}, J=10.4 \mathrm{~Hz}, 1 \mathrm{H}), 4.85(\mathrm{~d}, J=21.5 \mathrm{~Hz}, 1 \mathrm{H}), 4.58(\mathrm{~d}, J=$ $13.0 \mathrm{~Hz}, 1 \mathrm{H}), 4.49$ (d, $J=13.5 \mathrm{~Hz}, 1 \mathrm{H}), 3.81(\mathrm{~s}, 3 \mathrm{H}), 3.73-3.77(\mathrm{~m}, 1 \mathrm{H}), 3.31(\mathrm{dd}, J=3.2,6.8 \mathrm{~Hz}, 1 \mathrm{H})$, $2.43(\mathrm{~d}, J=4.0 \mathrm{~Hz}, 1 \mathrm{H}), \quad 2.08-2.18(\mathrm{~m}, 1 \mathrm{H}), 1.91-1.98(\mathrm{~m}, 3 \mathrm{H}), 1.08(\mathrm{~d}, J=7.2 \mathrm{~Hz}, 3 \mathrm{H}), 0.39(\mathrm{~s}, 3 \mathrm{H})$, 0.34 (s, 3H); ${ }^{13} \mathrm{C}$ NMR $\left(100 \mathrm{MHz}, \mathrm{CDCl}_{3}\right) \square 159.3,137.9,134.8,134.1,130.4,129.4,129.0,127.6,114.5$, 113.9, 85.5, 83.6, 74.9, 71.1, 69.3, 55.3, 39.2, 34.1, 20.3, 17.9, -3.8, -4.2; IR (neat) 3560, 3304, 2961, 1613, $1514 \mathrm{~cm}^{-1}$; HRMS (ES+) $\mathrm{m} / z$ for $\mathrm{C}_{26} \mathrm{H}_{34} \mathrm{O}_{3} \mathrm{SiNa}[\mathrm{M}+\mathrm{Na}]^{+}$calcd 445.2175, found 445.2176.

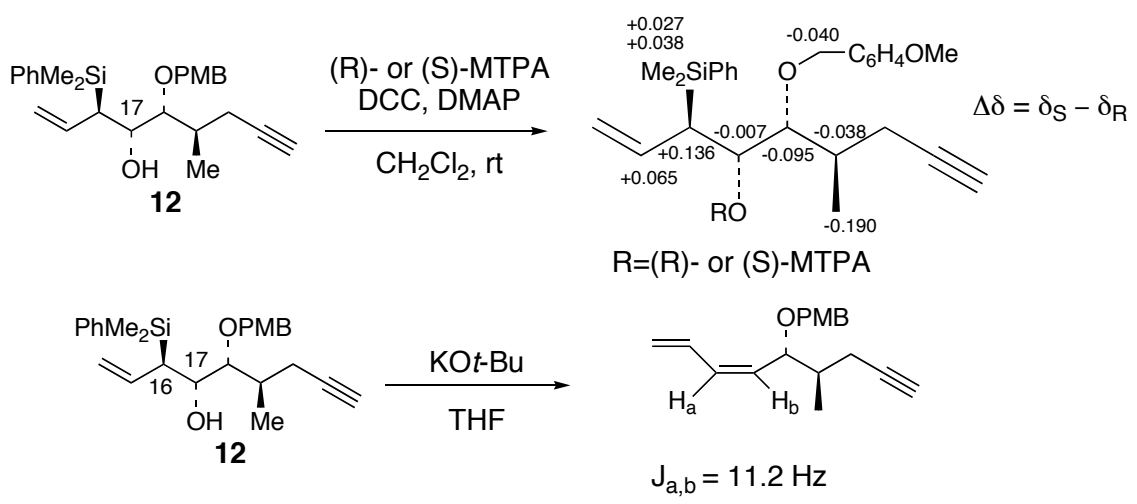

Scheme 1. Absolute and Relative Stereochemical Assignment of $\mathbf{1 2}$ 
The absolute stereochemistry of the $\mathrm{C}(17)$ hydroxyl was confirmed by application of the modified Mosher ester analysis (Scheme 1). In addition, the C(16)-C(17) relative stereochemistry was verified as anti by Peterson elimination of $\mathbf{1 2}$ to afford the corresponding $Z$ diene.

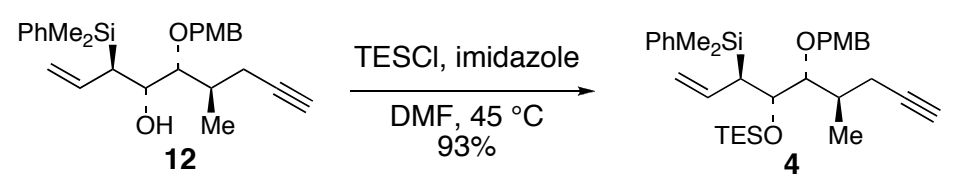

\section{1-[(1R,2S,3R)-3-(Dimethyl-phenyl-silanyl)-1-((R)-1-methyl-but-3-ynyl)-2-triethylsilanyloxy-} pent-4-enyloxymethyl]-4-methoxy-benzene (4) To a solution of 12 (1.01 g, $2.39 \mathrm{mmol})$ in DMF (2.5 $\mathrm{mL})$ was added imidazole $(0.50 \mathrm{~g}, 7.4 \mathrm{mmol})$ and TESCl $(1.21 \mathrm{~mL}, 7.17 \mathrm{mmol})$. The reaction was heated to $45{ }^{\circ} \mathrm{C}$ for $17 \mathrm{~h}$ and then quenched with water $(15 \mathrm{~mL})$ and extracted with $\mathrm{Et}_{2} \mathrm{O}(25 \mathrm{~mL} \times 3)$. The organic phase was washed with brine, dried over anhydrous $\mathrm{MgSO}_{4}$, filtered and concentrated. The crude product was purified by flash column chromatography to afford $4(1.19 \mathrm{~g}, 93 \%)$ as a colorless oil: [ $\square]_{\mathrm{D}}^{25}$ $=+31^{\circ}\left(c 1.30, \mathrm{CHCl}_{3}\right) ;{ }^{1} \mathrm{H}$ NMR $\left(400 \mathrm{MHz}, \mathrm{CDCl}_{3}\right) \square 7.49-7.52(\mathrm{~m}, 2 \mathrm{H}), 7.29-7.35(\mathrm{~m}, 3 \mathrm{H}), 7.18(\mathrm{~d}, J=$ $8.8 \mathrm{~Hz}, 2 \mathrm{H}), 6.86(\mathrm{~d}, J=8.8 \mathrm{~Hz}, 2 \mathrm{H}), 6.12(\mathrm{dt}, J=10.8,17.2 \mathrm{~Hz}, 1 \mathrm{H}), 4.91(\mathrm{dd}, J=10.4,2.0 \mathrm{~Hz}, 1 \mathrm{H})$, $4.79(\mathrm{dd}, J=17.2,1.6 \mathrm{~Hz}, 1 \mathrm{H}), 4.30(\mathrm{AB}, J=18.8 \mathrm{~Hz}, 1 \mathrm{H}), 4.27(\mathrm{~d}, J=12.4 \mathrm{~Hz}, 1 \mathrm{H}), 4.50-4.70(\mathrm{~m}$, $1 \mathrm{H}), 3.81(\mathrm{~s}, 3 \mathrm{H}), 3.22(\mathrm{dd}, J=3.6,8.4 \mathrm{~Hz}, 1 \mathrm{H}), 2.31-2.36(\mathrm{~m}, 2 \mathrm{H}), 2.19(\mathrm{dt}, J=3.2,16.8 \mathrm{~Hz}, 1 \mathrm{H})$, 2.09-2.13 (m, 1H), $1.94($ app t, $J=2.4 \mathrm{~Hz}, 1 \mathrm{H}), 1.02$ (d, $J=6.4 \mathrm{~Hz}, 3 \mathrm{H}), 0.91$ (t, $J=8.4 \mathrm{~Hz}, 9 \mathrm{H}), 0.50$ $0.57(\mathrm{~m}, 6 \mathrm{H}), \quad 0.34(\mathrm{~s}, 3 \mathrm{H}), 0.27(\mathrm{~s}, 3 \mathrm{H}) ;{ }^{13} \mathrm{C} \mathrm{NMR}\left(100 \mathrm{MHz}, \mathrm{CDCl}_{3}\right) \square 159.1,138.0,136.5,134.3$, 130.8, 129.3, 128.9, 127.6, 113.6, 113.2, 85.3, 83.4, 72.6, 71.5, 69.5, 55.2, 37.0, 32.9, 22.8, 17.0 , 7.1, 5.6, $-3.2,-4.2$; IR (neat) $3309,2956,2877,1613,1514,1248 \mathrm{~cm}^{-1}$; HRMS (ES+) $\mathrm{m} / z$ for $\mathrm{C}_{32} \mathrm{H}_{48} \mathrm{O}_{3} \mathrm{Si}_{2} \mathrm{Na}$ $[\mathrm{M}+\mathrm{Na}]^{+}$calcd 559.3040, found 559.3044.

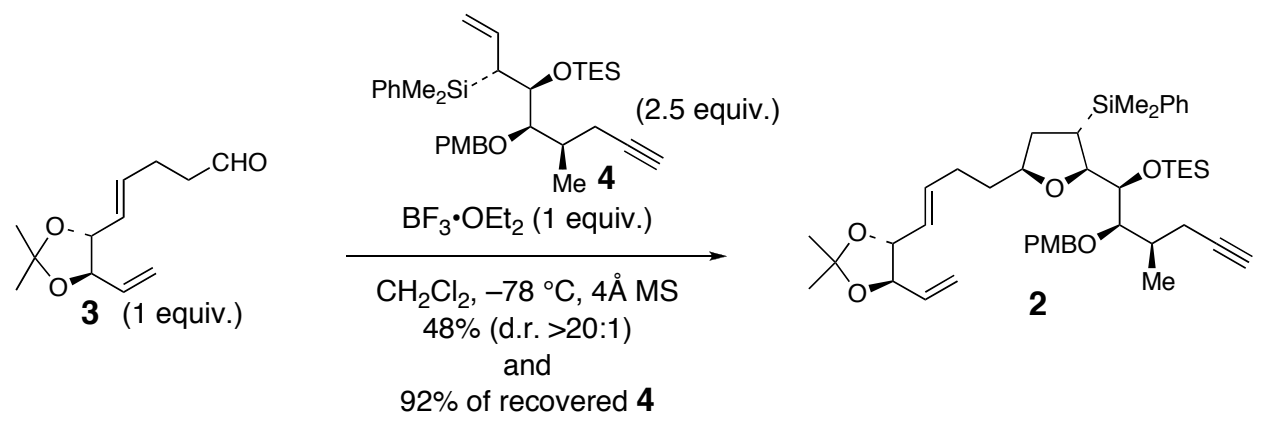

(4R,5R)-4-((E)-4-\{(2S,4S,5R)-4-(Dimethyl-phenyl-silanyl)-5-[(1S,2R,3R)-2-(4-methoxybenzyloxy)-3-methyl-1-triethylsilanyloxy-hex-5-ynyl]-tetrahydro-furan-2-yl\}-but-1-enyl)-2,2dimethyl-5-vinyl-[1,3]dioxolane (2) A 25-mL round bottom flask was charged with aldehyde 3 (1.06 g, 
$5.04 \mathrm{mmol})$, allylsilane 4 (8.12 g, $15.1 \mathrm{mmol})$, activated $4 \AA$ molecular sieves $(2.0 \mathrm{~g})$ and dichloromethane $(10 \mathrm{~mL})$. The slurry was stirred at room temperature for $10 \mathrm{~min}$ and then cooled to -78 ${ }^{\circ} \mathrm{C}$. The cooled reaction was then treated with $\mathrm{BF}_{3} \cdot \mathrm{OEt}_{2}(0.64 \mathrm{~mL}, 5.04 \mathrm{mmol}$, freshly distilled from calcium hydride). The reaction mixture was stirred at $-78{ }^{\circ} \mathrm{C}$ for $21 \mathrm{~h}$ and then quenched with triethylamine $(1 \mathrm{~mL})$. The mixture was diluted with sat. aq. $\mathrm{NaHCO}_{3}(60 \mathrm{~mL})$ and $\mathrm{Et}_{2} \mathrm{O}(50 \mathrm{~mL})$ and filtered through Celite. The aqueous phase was extracted with $\mathrm{Et}_{2} \mathrm{O}(30 \mathrm{~mL} \times 3)$. The organic phase was washed with brine, dried over anhydrous $\mathrm{MgSO}_{4}$, filtered and concentrated. Purfication of the crude product by flash column chromatography afforded 2 (1.19 g, 48\%; (6.27 g of allylsilane 4 was recovered) ) as a colorless oil with $>20: 1$ diastereoselectivity: $[\square]_{\mathrm{D}}^{25}=+23^{\circ}\left(\mathrm{c} 0.76, \mathrm{CHCl}_{3}\right)$; ${ }^{1} \mathrm{H}$ NMR $\left(400 \mathrm{MHz}, \mathrm{CDCl}_{3}\right) \square 7.47$ (app dd, $\left.J=1.6,7.2 \mathrm{~Hz}, 2 \mathrm{H}\right), 7.29-7.38(\mathrm{~m}, 3 \mathrm{H}), 7.24(\mathrm{~d}, J=8.4 \mathrm{~Hz}, 2 \mathrm{H}), 6.87$ $(\mathrm{d}, J=8.4 \mathrm{~Hz}, 2 \mathrm{H}), 5.74-5.82(\mathrm{~m}, 2 \mathrm{H}), 5.41(\mathrm{~b} \mathrm{dd}, J=7.2,15.2 \mathrm{~Hz}, 1 \mathrm{H}), 5.32(\mathrm{~d}, J=17.6 \mathrm{~Hz}, 1 \mathrm{H}), 5.22$ $(\mathrm{d}, J=10.4 \mathrm{~Hz}, 1 \mathrm{H}), 4.51(\mathrm{~d}, J=10.8 \mathrm{~Hz}, 1 \mathrm{H}), 4.39$ (d, $J=10.8 \mathrm{~Hz}, 1 \mathrm{H}), 4.05$ (app dd, $J=6.8,12.4 \mathrm{~Hz}$, $3 \mathrm{H}), 3.81(\mathrm{~s}, 3 \mathrm{H}), 3.71(\mathrm{~m}, 1 \mathrm{H}), 3.58(\mathrm{~d}, J=5.6 \mathrm{~Hz}, 1 \mathrm{H}), 3.32($ app t, $J=6.8 \mathrm{~Hz}, 1 \mathrm{H}), 2.03-2.34(\mathrm{~m}, 5 \mathrm{H})$, $1.94(\mathrm{t}, J=2.4 \mathrm{~Hz}, 1 \mathrm{H}), 1.79-1.83(\mathrm{~m}, 1 \mathrm{H}), 1.58-1.69(\mathrm{~m}, 3 \mathrm{H}), 1.44(\mathrm{~s}, 3 \mathrm{H}), 1.43(\mathrm{~s}, 3 \mathrm{H}), 1.10(\mathrm{~d}, J=6.8$ $\mathrm{Hz}, 3 \mathrm{H}), 0.95(\mathrm{t}, J=8.0 \mathrm{~Hz}, 9 \mathrm{H}), 0.51-0.61(\mathrm{~m}, 6 \mathrm{H}), 0.32(\mathrm{~s}, 3 \mathrm{H}), 0.32(\mathrm{~s}, 3 \mathrm{H}) ;{ }^{13} \mathrm{C} \mathrm{NMR}(100 \mathrm{MHz}$, $\left.\mathrm{CDCl}_{3}\right) \square 158.9,137.6,136.4,134.3,133.8,130.9,129.1,128.9,127.8,125.5,118.2,113.2,108.6,83.8$, 83.2, 82.1, 80.2, 78.5, 77.2, 73.6, 73.1, 69.2, 55.1, 35.2, 34.5. 34.3, 29.3, 27.0, 26.9, 26.2, 22.1, 17.1, 7.1, 5.2, -4.1; IR (neat) 3309, 2955, 2250, 2115, 1614, $1514 \mathrm{~cm}^{-1}$; HRMS (ES+) $\mathrm{m} / z$ for $\mathrm{C}_{44} \mathrm{H}_{66} \mathrm{O}_{6} \mathrm{Si}_{2} \mathrm{Na}$ $[\mathrm{M}+\mathrm{Na}]^{+}$calcd 769.4296 , found 769.4307 .

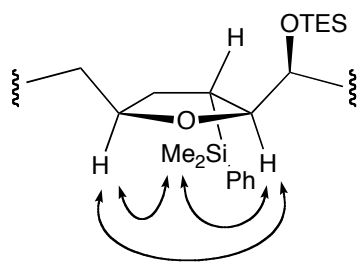

Figure 1. Observed nOe's verifying 2,5-cis-THF stereochemistry in 2.

The 2,5-cis relative stereochemistry about the THF ring in [3+2] adduct 2 was confirmed by the observed nOe correlation peaks shown in Figure 1.
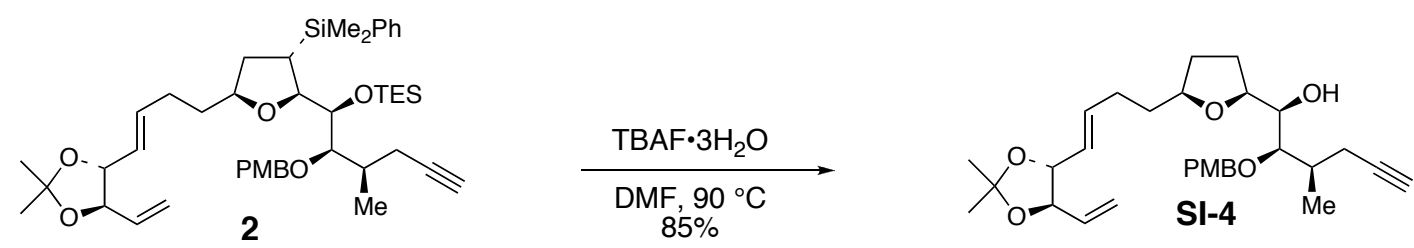

(1R,2R,3R)-1-\{(2S,5S)-5-[(E)-4-((4R,5R)-2,2-Dimethyl-5-vinyl-[1,3]dioxolan-4-yl)-but-3enyl]-tetrahydro-furan-2-yl\}-2-(4-methoxy-benzyloxy)-3-methyl-hex-5-yn-1-ol (SI-4) To [3+2] 
adduct $2(1.81 \mathrm{~g}, 2.42 \mathrm{mmol})$ in DMF $(2.5 \mathrm{~mL})$ was added TBAF• $3 \mathrm{H}_{2} \mathrm{O}(3.82 \mathrm{~g}, 12.1 \mathrm{mmol}$, purchased from ACROS). The reaction was fitted with a condenser and placed in a $90{ }^{\circ} \mathrm{C}$ oil bath for $72 \mathrm{~h}$. More $\mathrm{TBAF} \cdot 3 \mathrm{H}_{2} \mathrm{O}(2.0 \mathrm{~g}, 6.34 \mathrm{mmol})$ was added to the reaction three times during the $72 \mathrm{~h}$ period; at hour 8 , hour 32 and hour 56 . After $72 \mathrm{~h}$, the reaction was diluted with $\mathrm{pH} 7$ buffer $(50 \mathrm{~mL})$ and $\mathrm{Et}_{2} \mathrm{O}(30 \mathrm{~mL})$. The aqueous phase was extracted with $\mathrm{Et}_{2} \mathrm{O}(30 \mathrm{~mL}$ x 3). The organic phase was washed with brine, dried over anhydrous $\mathrm{MgSO}_{4}$, filtered and concentrated. The crude product was purified by flash column chromatography to afford SI-4 $(1.03 \mathrm{~g}, 85 \%)$ as a colorless oil: $[\square]_{\mathrm{D}}^{25}=+6.4^{\circ}\left(c 0.39, \mathrm{CHCl}_{3}\right) ;{ }^{1} \mathrm{H} \mathrm{NMR}$ $\left(400 \mathrm{MHz}, \mathrm{CDCl}_{3}\right) \square 7.28(\mathrm{~d}, J=8.8 \mathrm{~Hz}, 2 \mathrm{H}), 6.85(\mathrm{~d}, J=8.8 \mathrm{~Hz}, 2 \mathrm{H}), 5.73-5.81(\mathrm{~m}, 2 \mathrm{H}), 5.41$ (app bddd, $J=1.6,6.0,15.6 \mathrm{~Hz}, 1 \mathrm{H}), 5.32(\mathrm{~d}, J=16.4 \mathrm{~Hz}, 1 \mathrm{H}), 5.21(\mathrm{dd}, J=1.2,10.4 \mathrm{~Hz}, 1 \mathrm{H}), 4.58$ (app q, $J=10.8$ $\mathrm{Hz}, 2 \mathrm{H}$ ), 4.03 (app q, $J=6.8 \mathrm{~Hz}, 2 \mathrm{H}$ ), 3.93 (app q, $J=7.2 \mathrm{~Hz}, 1 \mathrm{H}$ ), 3.85 (quint., $J=6.4 \mathrm{~Hz}, 1 \mathrm{H}$ ), 3.78 (s, $3 \mathrm{H}), 3.45-3.50(\mathrm{~m}, 1 \mathrm{H}), 3.35(\mathrm{dd}, J=2.0,8.0 \mathrm{~Hz}, 1 \mathrm{H}), 5.23(\mathrm{bd}, J=6.8 \mathrm{~Hz}, 1 \mathrm{H}), 2.34(\mathrm{ddq}, J=2.4,6.8$, $16.8 \mathrm{~Hz}, 2 \mathrm{H}), 2.05-2.24(\mathrm{~m}, 3 \mathrm{H}), 1.99(\mathrm{t}, J=2.4 \mathrm{~Hz}, 1 \mathrm{H}), 1.89-1.95(\mathrm{~m}, 1 \mathrm{H}), 1.78-1.86(\mathrm{~m}, 1 \mathrm{H}), 1.64-$ $1.75(\mathrm{~m}, 2 \mathrm{H}), 1.46-1.60(\mathrm{~m}, 2 \mathrm{H}), 1.43(\mathrm{~s}, 3 \mathrm{H}), 1.42(\mathrm{~s}, 3 \mathrm{H}), 1.08(\mathrm{~d}, J=6.8 \mathrm{~Hz}, 3 \mathrm{H}) ;{ }^{13} \mathrm{C} \mathrm{NMR}(100 \mathrm{MHz}$, $\left.\mathrm{CDCl}_{3}\right) \square 159.2,135.9,134.2,130.4,129.5,125.9,118.4,113.6,108.7,83.1,82.1,82.0,81.6,80.4,79.2$, 73.5, 73.1, 69.9, 55.1, 35.1, 34.2, 31.0, 29.0, 27.0, 27.0, 21.8, 16.2; IR (neat) 3536, 3296, 2984, 2934, 1613, 1514, $1248 \mathrm{~cm}^{-1}$; HRMS (ES+) $m / z$ for $\mathrm{C}_{30} \mathrm{H}_{42} \mathrm{O}_{6} \mathrm{Na}[\mathrm{M}+\mathrm{Na}]^{+}$calcd 521.2879, found 521.2879.
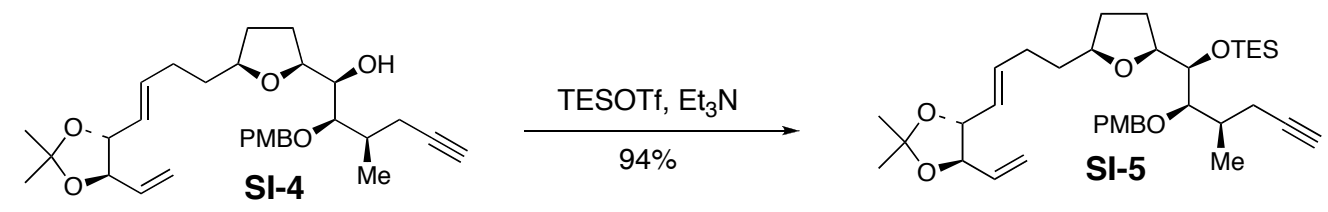

\section{[(1R,2R,3R)-1-\{(2S,5S)-5-[(E)-4-((4R,5R)-2,2-Dimethyl-5-vinyl-[1,3]dioxolan-4-yl)-but-3-} enyl]-tetrahydro-furan-2-yl\}-2-(4-methoxy-benzyloxy)-3-methyl-hex-5-ynyloxyl-triethyl-silane (SI5) To a $0{ }^{\circ} \mathrm{C}$ solution of alcohol SI-4 $(1.2 \mathrm{~g}, 2.41 \mathrm{mmol})$ and triethylamine $(0.67 \mathrm{~mL}, 4.82 \mathrm{mmol})$ in dichloromethane $(8 \mathrm{~mL})$ was added TESOTf $(0.65 \mathrm{~mL}, 2.89 \mathrm{mmol})$. After $5 \mathrm{~min}$ the reaction was quenched with sat. aq. $\mathrm{NaHCO}_{3}(30 \mathrm{~mL})$ and $\mathrm{Et}_{2} \mathrm{O}(30 \mathrm{~mL})$. The aqueous phase was extracted with $\mathrm{Et}_{2} \mathrm{O}$ $(30 \mathrm{~mL} \times 3)$. The organic phase was washed with brine, dried over anhydrous $\mathrm{MgSO}_{4}$, filtere and concentrated. The crude product was purified by flash column chromatography to afford SI-5 (1.39 g, 94\%) as a colorless oil: $[\square]_{\mathrm{D}}^{25}=+11^{\circ}\left(c 0.36, \mathrm{CHCl}_{3}\right) ;{ }^{1} \mathrm{H}$ NMR $\left(400 \mathrm{MHz}, \mathrm{CDCl}_{3}\right) \square 7.25(\mathrm{~d}, J=8.8 \mathrm{~Hz}$, $2 \mathrm{H}), 6.87(\mathrm{~d}, J=8.8 \mathrm{~Hz}, 2 \mathrm{H}), 5.75-5.85(\mathrm{~m}, 2 \mathrm{H}), 5.44(\mathrm{bdd}, J=7.2,15.2 \mathrm{~Hz}, 1 \mathrm{H}), 5.34(\mathrm{~d}, J=17.2 \mathrm{~Hz}$, $1 \mathrm{H}), 5.23(\mathrm{dd}, J=0.8,10.4 \mathrm{~Hz}, 1 \mathrm{H}), 4.55(\mathrm{~s}, 2 \mathrm{H}), 4.05$ (app q, $J=6.4 \mathrm{~Hz}, 2 \mathrm{H}), 3.93$ (app q, $J=6.8 \mathrm{~Hz}$, $1 \mathrm{H}), 3.80(\mathrm{~s}, 3 \mathrm{H}), 3.75-3.79(\mathrm{~m}, 1 \mathrm{H}), 3.74(\mathrm{dd}, J=3.2,6.8 \mathrm{~Hz}, 1 \mathrm{H}), 3.29(\mathrm{dd}, J=3.2,8.8 \mathrm{~Hz}, 1 \mathrm{H}), 2.28-$ $2.40(\mathrm{~m}, 2 \mathrm{H}), 2.09-2.24(\mathrm{~m}, 3 \mathrm{H}), 1.97(\mathrm{t}, J=2.8 \mathrm{~Hz}, 1 \mathrm{H}), 1.79-1.94(\mathrm{~m}, 2 \mathrm{H}), 1.61-1.70(\mathrm{~m}, 2 \mathrm{H}), 1.51-$ $1.59(\mathrm{~m}, 2 \mathrm{H}), 1.45(\mathrm{~s}, 3 \mathrm{H}), 1.44(\mathrm{~s}, 3 \mathrm{H}), 1.10(\mathrm{~d}, J=6.8 \mathrm{~Hz}, 3 \mathrm{H}), 0.96(\mathrm{t}, J=8.0 \mathrm{~Hz}, 9 \mathrm{H}), 0.55-0.72(\mathrm{~m}$, 
$6 \mathrm{H}) ;{ }^{13} \mathrm{C}$ NMR (100 MHz, $\left.\mathrm{CDCl}_{3}\right) \square 159.0,136.3,134.3,131.0,129.0,125.7,118.4,113.6,108.8,83.2$, 83.1, 82.2, 82.2, 80.4, 78.2, 75.8, 71.9, 69.6, 55.2, 35.3, 33.2, 31.1, 29.2, 27.8, 27.0, 26.9, 22.5, 16.5, 7.0, 5.2; IR (neat) 3308, 2954, 2875, 1612, 1514, 1247, $1057 \mathrm{~cm}^{-1}$; HRMS (ES+) $\mathrm{m} / z$ for $\mathrm{C}_{36} \mathrm{H}_{56} \mathrm{O}_{6} \mathrm{SiNa}$ $[\mathrm{M}+\mathrm{Na}]^{+}$calcd 635.3744 , found 635.3754 .
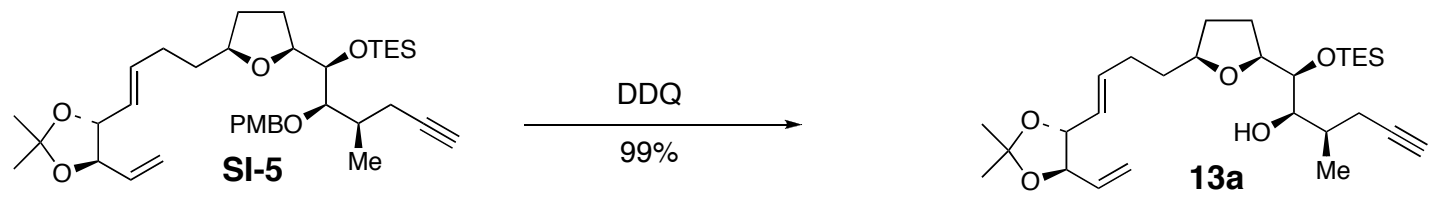

\section{(1S,2R,3R)-1-\{(2S,5S)-5-[(E)-4-((4R,5R)-2,2-Dimethyl-5-vinyl-[1,3]dioxolan-4-yl)-but-3-}

enyl]-tetrahydro-furan-2-yl\}-3-methyl-1-triethylsilanyloxy-hex-5-yn-2-ol (13a) To a $0{ }^{\circ} \mathrm{C}$ solution of SI-5 $(0.621 \mathrm{~g}, 1.01 \mathrm{mmol})$ in dichloromethane $(10 \mathrm{~mL})$ and $\mathrm{pH} 7$ buffer $(1 \mathrm{~mL})$ was added DDQ $(0.46 \mathrm{~g}$, $2.02 \mathrm{mmol})$. The reaction was stirred for $1 \mathrm{~h}$, and then quenched with sat. aq. $\mathrm{NaHCO}_{3}(40 \mathrm{~mL})$ and $\mathrm{Et}_{2} \mathrm{O}$ $(30 \mathrm{~mL})$. The aqueous phase was extracted with $\mathrm{Et}_{2} \mathrm{O}(30 \mathrm{~mL} \times 3)$. The organic phase was washed with brine, dried over anhydrous $\mathrm{MgSO}_{4}$, filtered and concentrated. Purification of the crude product by flash column chromatography afforded $13 a(0.49 \mathrm{~g}, 99 \%)$ as a colorless oil: $[\square]^{25}{ }_{\mathrm{D}}=+13^{\circ}\left(c 0.18, \mathrm{CHCl}_{3}\right) ;{ }^{1} \mathrm{H}$ $\operatorname{NMR}\left(400 \mathrm{MHz}, \mathrm{CDCl}_{3}\right) \square 5.74-5.83(\mathrm{~m}, 2 \mathrm{H}), 5.43$ (app bddd, $\left.J=1.2,6.0,15.2 \mathrm{~Hz}, 1 \mathrm{H}\right), 5.33(\mathrm{~d}, J=$ $17.2 \mathrm{~Hz}, 1 \mathrm{H}), 5.23(\mathrm{dd}, J=0.8,10.4 \mathrm{~Hz}, 1 \mathrm{H}), 4.05(\operatorname{app~q}, J=6.4 \mathrm{~Hz}, 2 \mathrm{H}), 3.76(\mathrm{~m}, 2 \mathrm{H}), 3.67$ (d, $J=7.2$ $\mathrm{Hz}, 1 \mathrm{H}), 3.18(\mathrm{t}, J=9.6 \mathrm{~Hz}, 1 \mathrm{H}), 2.50(\mathrm{~d}, J=9.6 \mathrm{~Hz}, 1 \mathrm{H}), 2.48(\mathrm{dt}, J=3.6,16.4 \mathrm{~Hz}, 1 \mathrm{H}), 2.08-2.20$ (m, $2 \mathrm{H}), 1.95(\mathrm{t}, J=2.4 \mathrm{~Hz}, 1 \mathrm{H}), 1.84-1.97(\mathrm{~m}, 2 \mathrm{H}), 1.74-1.80(\mathrm{~m}, 1 \mathrm{H}), 1.61-1.66(\mathrm{~m}, 1 \mathrm{H}), 1.59-1.46(\mathrm{~m}$, $3 \mathrm{H}), 1.44(\mathrm{~s}, 3 \mathrm{H}), 1.43(\mathrm{~s}, 3 \mathrm{H}), 0.99(\mathrm{~d}, J=6.8 \mathrm{~Hz}, 3 \mathrm{H}), 0.95$ (t, $J=8.0 \mathrm{~Hz}, 9 \mathrm{H}), 0.66$ (app dsept., $J=$ 7.6, $19.26 \mathrm{H}) ;{ }^{13} \mathrm{C}$ NMR $\left(100 \mathrm{MHz}, \mathrm{CDCl}_{3}\right) \square 136.2,134.3,125.9,118.5,108.8,83.1,82.2,82.2,81.3$, 78.7, 74.5, 74.4, 69.3, 35.7, 35.2, 30.8, 29.2, 27.4, 27.1, 27.0, 22.1, 15.7, 7.0, 5.3; IR (neat) 3524, 3310, 2954, 2875, 1379, 1238, $1054 \mathrm{~cm}^{-1}$; HRMS (ES+) $\mathrm{m} / z$ for $\mathrm{C}_{28} \mathrm{H}_{48} \mathrm{O}_{5} \mathrm{SiNa}[\mathrm{M}+\mathrm{Na}]^{+}$calcd 515.3169 , found 515.3171 . 

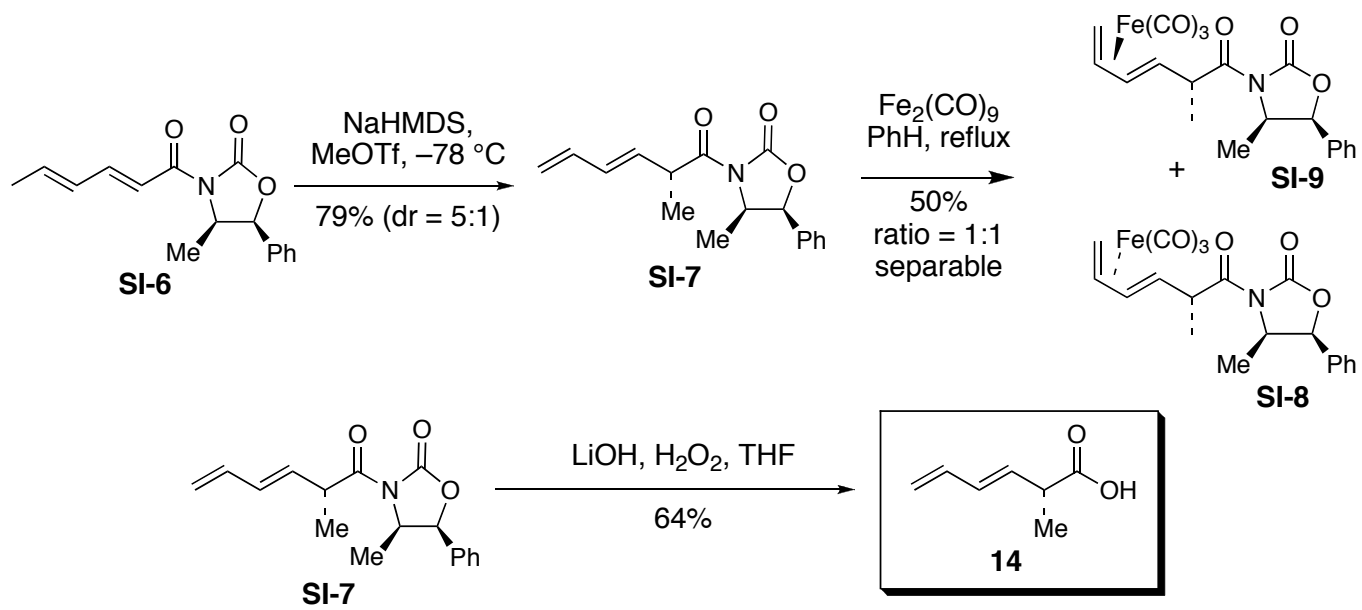

SI-8

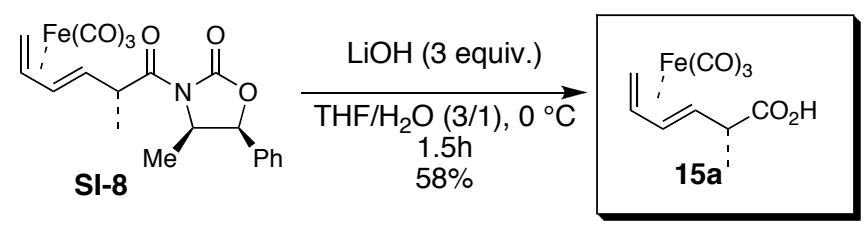

Scheme 2. Synthesis of acids 14 and 15a

The synthesis of acids $\mathbf{1 4}$ and $\mathbf{1 5 a}$ are shown in Scheme 2. Diastereoselective methylation of oxazolidinone SI-6 ${ }^{7}$ afforded oxazolidinone SI-7 (79\% yield, dr 5:1). Treatment of SI-7 with diiron nonacarbonyl afforded the diene complexed oxazolidinones SI-8 and SI-9 as a 1:1 separable mixture of diastereomers. Hydrolysis of oxazolidinone SI-7 afforded acid 14 (64\% yield). Hydrolysis of iron complexed oxazolidinone SI-8 afforded acid 15a (64\% yield).

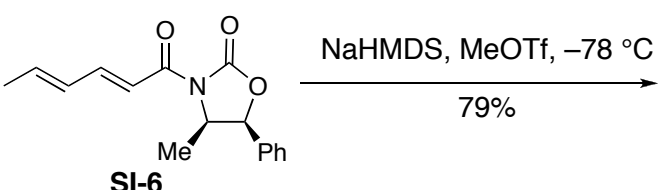

SI-6

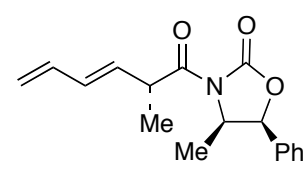

SI-7

(4R,5S)-4-Methyl-3-((E)-(R)-2-methyl-hexa-3,5-dienoyl)-5-phenyl-oxazolidin-2-one

To a $-78{ }^{\circ} \mathrm{C}$ solution of oxazolidinone SI-6 ${ }^{7}(8.75 \mathrm{~g}, 32.2 \mathrm{mmol})$ in THF $(90 \mathrm{~mL})$ was added NaHMDS $(8.28 \mathrm{~g}, 45.1 \mathrm{mmol})$ in THF $(10 \mathrm{~mL})$. The reaction was stirred at $-78{ }^{\circ} \mathrm{C}$ for $1 \mathrm{~h}$ and then treated with MeOTf $(5.47 \mathrm{~mL}, 48.4 \mathrm{mmol})$. After $3 \mathrm{~h}$, the reaction was quenched with sat. aq. $\mathrm{NH}_{4} \mathrm{Cl}(100 \mathrm{~mL})$ and $\mathrm{Et}_{2} \mathrm{O}(50 \mathrm{~mL})$. The aqueous phase was extracted with $\mathrm{Et}_{2} \mathrm{O}(50 \mathrm{~mL} \times 3)$. The organic phase was washed with brine, dried over anhydrous $\mathrm{MgSO}_{4}$, filtered, and concentrated. Analysis of the crude product by ${ }^{1} \mathrm{H}$ NMR indicated a 5:1 mixture of diastereomers in favor of SI-7. The crude product was purified by flash column chromatography in $20 \% \mathrm{Et}_{2} \mathrm{O} /$ hexane (minor isomer, $\mathrm{R}_{\mathrm{f}}=0.21$; major isomer, $\mathrm{R}_{\mathrm{f}}=0.36$ ) to afford SI-7 (7.30 g, 79\%) as a colorless oil: $[\square]^{25}=27^{\circ}\left(c 0.55, \mathrm{CHCl}_{3}\right) ;{ }^{1} \mathrm{H}$ NMR $\left(400 \mathrm{MHz}, \mathrm{CDCl}_{3}\right) \square 7.35$ $7.44(\mathrm{~m}, 3 \mathrm{H}), 7.30-7.32(\mathrm{~m}, 2 \mathrm{H}), 6.20-6.37$ (m, 2H), $5.83(\mathrm{dd}, J=8.4,15.2 \mathrm{~Hz}, 1 \mathrm{H}), 5.66$ (d, $J=7.2 \mathrm{~Hz}$, 
1H), 5.21 (app d, $J=17.6 \mathrm{~Hz}, 1 \mathrm{H}), 5.09$ (app d, $J=10.8 \mathrm{~Hz}, 1 \mathrm{H}), 4.53$ (quint., $J=7.6 \mathrm{~Hz}, 1 \mathrm{H}$ ), 4.74 (quint., $J=6.8 \mathrm{~Hz}, 1 \mathrm{H}), 1.33(\mathrm{~d}, J=7.2 \mathrm{~Hz}, 3 \mathrm{H}), 0.90(\mathrm{~d}, J=6.4 \mathrm{~Hz}, 3 \mathrm{H}) ;{ }^{13} \mathrm{C}$ NMR $\left(100 \mathrm{MHz}, \mathrm{CDCl}_{3}\right)$ $\mathrm{\square} 174.4,152.6,136.5,133.2,132.7,132.6,128.7,128.7,125.6,117.3,78.8,55.1,40.8,17.3$, 14.5; IR (neat) 2981, 2934, 1782, 1699, 1356, $1197 \mathrm{~cm}^{-1}$; HRMS (ES+) $m / z$ for $\mathrm{C}_{17} \mathrm{H}_{21} \mathrm{NO}_{4} \mathrm{Na}[\mathrm{M}+\mathrm{Na}]^{+}$calcd 308.1263 , found 308.1262 .

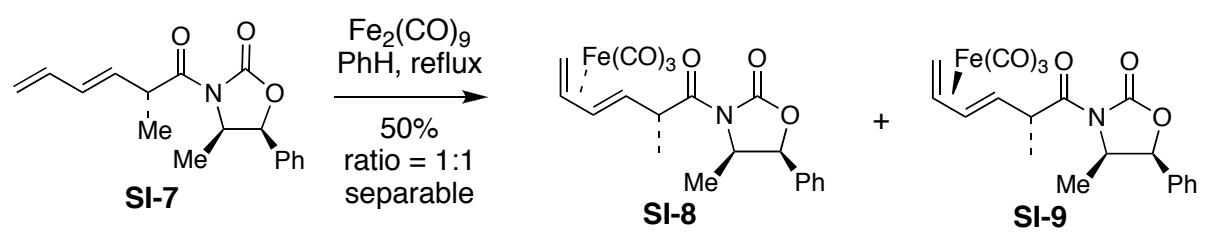

Tricarbonyl[(4R,5S)-4-Methyl-3-((E)-(2S,3R)-2-methyl-hexa-3,5-dienoyl)-5-phenyloxazolidin-2-one]iron (SI-8) and Tricarbonyl[(4R,5S)-4-Methyl-3-((E)-(2S,3S)-2-methyl-hexa-3,5dienoyl)-5-phenyl-oxazolidin-2-one]iron (SI-9) To oxazolidinone SI-7 ( $2.0 \mathrm{~g}, 7.0 \mathrm{mmol}$ ) in benzene $(23 \mathrm{~mL})$ was added diiron(nonacarbonyl) $(3.8 \mathrm{~g}, 10.5 \mathrm{mmol})$. The reaction was fitted with a condenser and refluxed for a total of $24 \mathrm{~h}$. Additional diiron(nonacarbonyl) (1.5 g, $4.12 \mathrm{mmol}$ ) and benzene (10 mL) was added to the reaction at hour 6 and hour 20. After 24 hours, the reaction was cooled to room temp, filtered through Celite with an $\mathrm{Et}_{2} \mathrm{O}(25 \mathrm{~mL})$ wash and concentrated to afford a 1:1 mixture of SI-8 and SI-9. The crude product mixture was separated by flash column chromatography $\left(10 \% \mathrm{Et}_{2} \mathrm{O} /\right.$ hexanes to 40\% $\mathrm{Et}_{2} \mathrm{O} /$ hexanes with SI-9 (0.78 g) eluting before SI-8 (0.71 g), SI-8 and SI-9 combined yield of 50\%).

Spectroscopic properties of SI-8 (yellow solid): $\mathrm{R}_{\mathrm{f}}=0.33\left(30 \% \mathrm{Et}_{2} \mathrm{O} /\right.$ hexane); $[\square]^{25}{ }_{\mathrm{D}}=+8^{\circ}(\mathrm{c}$ 0.1, $\left.\mathrm{CHCl}_{3}\right) ;{ }^{1} \mathrm{H}$ NMR $\left(400 \mathrm{MHz}, \mathrm{CDCl}_{3}\right) \square 7.36-7.45(\mathrm{~m}, 3 \mathrm{H}), 7.36(\operatorname{app~d}, J=6.8 \mathrm{~Hz}, 2 \mathrm{H}), 5.71(\mathrm{~d}, J=$ $7.2 \mathrm{~Hz}, 1 \mathrm{H}), 5.46$ (dd, $J=4.8,8.4 \mathrm{~Hz}, 1 \mathrm{H}), 5.22-5.27$ (m, 1H), 4.76 (quint., $J=6.8 \mathrm{~Hz}, 1 \mathrm{H}$ ), 3.82-3.40 $(\mathrm{m}, 1 \mathrm{H}), 1.78(\operatorname{app} \mathrm{dd}, J=1.6,6.8 \mathrm{~Hz}, 1 \mathrm{H}), 1.37$ (d, $J=6.8 \mathrm{~Hz}, 3 \mathrm{H}), 1.15(\operatorname{app~t}, J=8.8 \mathrm{~Hz}, 1 \mathrm{H}), 0.88(\mathrm{~d}$, $J=6.4 \mathrm{~Hz}, 3 \mathrm{H}), 0.39$ (app dd, $J=2.0,9.6 \mathrm{~Hz}, 1 \mathrm{H}) ;{ }^{13} \mathrm{C} \mathrm{NMR}\left(100 \mathrm{MHz}, \mathrm{CDCl}_{3}\right) \square 210.8,175.2,152.9$, 133.2, 128.9, 128.8, 125.7, 86.4, 81.9, 78.9, 64.7, 55.1, 41.0, 40.4, 19.9, 14.5; IR (neat) 2984, 2047, 1970, 1779, 1697, $1355 \mathrm{~cm}^{-1}$; HRMS (ES+) $m / z$ for $\mathrm{C}_{20} \mathrm{H}_{19} \mathrm{FeNO}_{6} \mathrm{Na}[\mathrm{M}+\mathrm{Na}]^{+}$calcd 448.0459, found 448.0464.

Spectroscopic properties of SI-9 (yellow solid): $\mathrm{R}_{\mathrm{f}}=0.50\left(30 \% \mathrm{Et}_{2} \mathrm{O} / \mathrm{hexane}\right) ;[\square]_{\mathrm{D}}^{25}=-83^{\circ}(\mathrm{c}$ 0.1, $\left.\mathrm{CHCl}_{3}\right) ;{ }^{1} \mathrm{H}$ NMR $\left(400 \mathrm{MHz}, \mathrm{CDCl}_{3}\right) \square 7.30-7.45(\mathrm{~m}, 5 \mathrm{H}), 5.71(\mathrm{~d}, J=7.2 \mathrm{~Hz}, 1 \mathrm{H}), 5.28-5.33(\mathrm{~m}$, 2H), 4.84 (quint., $J=6.8 \mathrm{~Hz}, 1 \mathrm{H}), 3.65-3.78(\mathrm{~m}, 1 \mathrm{H}), 1.40(\mathrm{~d}, J=6.8 \mathrm{~Hz}, 3 \mathrm{H}), 1.36$ (app dd, $J=7.6,10.0$ $\mathrm{Hz}, 3 \mathrm{H}), 0.92(\mathrm{~d}, J=6.8 \mathrm{~Hz}, 3 \mathrm{H}), 0.45(\operatorname{app} \mathrm{dd}, J=2.8,8.8 \mathrm{~Hz}, 1 \mathrm{H}) ;{ }^{13} \mathrm{C}$ NMR $\left(100 \mathrm{MHz}, \mathrm{CDCl}_{3}\right)$ ○211.4, 174.6, 152.6, 133.2, 128.7, 125.6, 87.1, 82.7, 79.2, 62.9, 55.4, 43.4, 40.4, 26.3, 22.3, 14.3; IR (neat) 2977, 2046, 1978, 1782, 1700, $1342 \mathrm{~cm}^{-1}$; HRMS (ES+) $m / z$ for $\mathrm{C}_{20} \mathrm{H}_{19} \mathrm{FeNO}{ }_{6} \mathrm{Na}[\mathrm{M}+\mathrm{Na}]^{+}$calcd 448.0459 , found 448.0462 . 


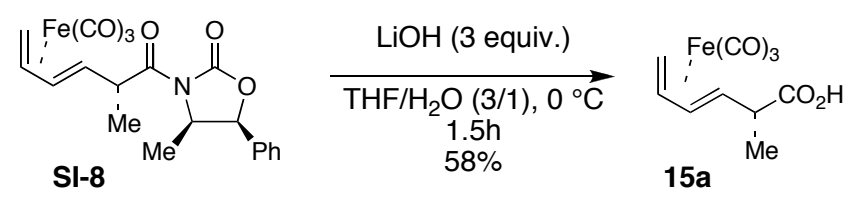

Tricarbonyl[(E)-(2S,3R)-2-Methyl-hexa-3,5-dienoic acid]iron (15a) To a $0{ }^{\circ} \mathrm{C}$ solution of oxazolidinone SI-8 (1.15 g, $2.70 \mathrm{mmol})$ in THF $(21 \mathrm{~mL})$ and water $(7 \mathrm{~mL})$ was added LiOH $(0.194 \mathrm{~g}$, $8.11 \mathrm{mmol})$. The reaction was stirred for $1.5 \mathrm{~h}$ and then quenched with $1 \mathrm{M} \mathrm{HCl}(25 \mathrm{~mL})$ and $\mathrm{Et}_{2} \mathrm{O}(25$ $\mathrm{mL})$. The aqueous phase was extracted with $\mathrm{Et}_{2} \mathrm{O}(25 \mathrm{~mL} \times 3)$. The organic phase was dried over anhydrous $\mathrm{MgSO}_{4}$, filtered and concentrated. The crude carboxylic acid was purified by flash column chromatography to afford $15 \mathrm{a}(0.423 \mathrm{~g}, 58 \%)$ as a yellow solid: $[\square]^{25}{ }_{\mathrm{D}}=+11^{\circ}\left(c 0.1, \mathrm{CHCl}_{3}\right) ;{ }^{1} \mathrm{H} \mathrm{NMR}$ $\left(400 \mathrm{MHz}, \mathrm{CDCl}_{3}\right) \square 10.40$ (bs, 1H), 5.38-5.44 (m, 1H), 5.25-5.30 (m, 1H), $2.32(\mathrm{bs}, 1 \mathrm{H}), 1.81$ (d, $J=6.4$ $\mathrm{Hz}, 1 \mathrm{H}), 1.35(\mathrm{~d}, J=6.4 \mathrm{~Hz}, 3 \mathrm{H}), 0.94($ app t, $J=9.2 \mathrm{~Hz}, 1 \mathrm{H}), 0.38(\mathrm{~d}, J=7.6 \mathrm{~Hz}, 1 \mathrm{H}) ;{ }^{13} \mathrm{C} \mathrm{NMR}(100$ $\left.\mathrm{MHz}, \mathrm{CDCl}_{3}\right) \square 211.1,181.1,87.1,82.3,63.1,44.0,40.5,19.0$; IR (neat) 2983, 2049, 1971, $1705 \mathrm{~cm}^{-1}$; HRMS (EI+) $\mathrm{m} / \mathrm{z}$ for $\mathrm{C}_{9} \mathrm{H}_{10} \mathrm{FeO}_{4}[\mathrm{M}-\mathrm{CO}]^{+}$calcd 237.9928, found 237.9918. The spectroscopic data obtained for 15a are fully consistent with data for racemic 15a previously published by Donaldson. ${ }^{8}$

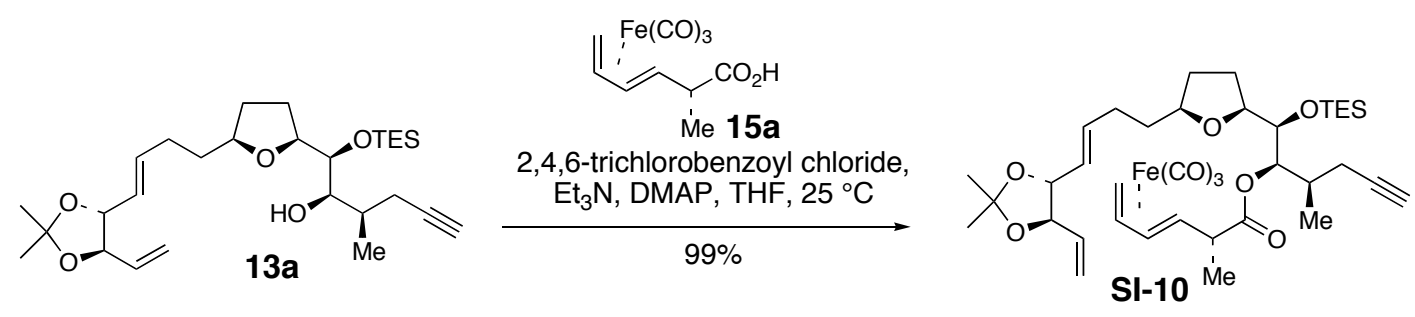

Tricarbonyl[(E)-(2S,3R)-2-Methyl-hexa-3,5-dienoic acid (1R,2R)-1-((R)-\{(2S,5S)-5-[(E)-4((4R,5R)-2,2-dimethyl-5-vinyl-[1,3] dioxolan-4-yl)-but-3-enyl]-tetrahydro-furan-2-yl\}triethylsilanyloxy-methyl)-2-methyl-pent-4-ynyl ester]iron (SI-10). To $0{ }^{\circ} \mathrm{C}$ solution of 13a (120 mg, $0.244 \mathrm{mmol}), 15 \mathrm{a}(105 \mathrm{mg}, 0.390 \mathrm{mmol})$, triethylamine $(0.12 \mathrm{~mL}, 0.854 \mathrm{mmol})$, and DMAP (30 $\mathrm{mg}$, $0.244 \mathrm{mmol})$ in THF $(0.5 \mathrm{~mL})$ was added 2,4,6-trichlorobenzoyl chloride $(61 \mathrm{LL}, 0.390 \mathrm{mmol})$. The redish brown solution was stirred at $0{ }^{\circ} \mathrm{C}$ for $1 \mathrm{~h}$ and allowed to warm to room temperature over another 1 h. After complete consumption of 13a was observed by TLC analysis, the reaction was quenched with sat. aq. $\mathrm{NaHCO}_{3}(30 \mathrm{~mL})$ and $\mathrm{Et}_{2} \mathrm{O}(30 \mathrm{~mL})$. The aqueous phase was extracted with $\mathrm{Et}_{2} \mathrm{O}(25 \mathrm{~mL} \times 3)$. The organic phase was washed with sat. aq. $\mathrm{NH}_{4} \mathrm{Cl}$, brine, dried over anhydrous $\mathrm{MgSO}_{4}$, filtered and concentrated. Purification of the crude product by flash column chromatography afforded SI-10 (179 mg, 99\%) as a colorless oil: $[\square]_{\mathrm{D}}^{25}=+13^{\circ}\left(\mathrm{c} 0.18, \mathrm{CHCl}_{3}\right) ;{ }^{1} \mathrm{H}$ NMR $\left(400 \mathrm{MHz}, \mathrm{CDCl}_{3}\right) \square$ 5.74-5.81 (m, 2H), 5.43 (app dd, $J=4.8,8.4 \mathrm{~Hz}, 2 \mathrm{H}), 5.33(\mathrm{~d}, J=16.8 \mathrm{~Hz}, 1 \mathrm{H}), 5.21-5.26(\mathrm{~m}, 1 \mathrm{H}), 5.22$ (d, $J=11.6 \mathrm{~Hz}$, $1 \mathrm{H}), 4.69(\mathrm{dd}, J=1.2,9.2 \mathrm{~Hz}, 1 \mathrm{H}), 4.04$ (app q, $J=6.8 \mathrm{~Hz}, 2 \mathrm{H}), 3.72$ (quint., $J=5.6,1 \mathrm{H}), 3.67$ (dd, $J=$ 1.6, 7.6 Hz, 1H), $3.60(\operatorname{app~q}, J=8.0 \mathrm{~Hz}, 1 \mathrm{H}), 1.99-2.32(\mathrm{~m}, 7 \mathrm{H}), 1.94(\mathrm{t}, J=2.8 \mathrm{~Hz}, 1 \mathrm{H}), 1.73-1.88(\mathrm{~m}$, 
$3 \mathrm{H}), 1.50-1.66(\mathrm{~m}, 2 \mathrm{H}), 1.38-1.48(\mathrm{~m}, 1 \mathrm{H}), 1.44(\mathrm{~s}, 3 \mathrm{H}), 1.43(\mathrm{~s}, 3 \mathrm{H}), 1.31$ (d, $J=6.8 \mathrm{~Hz}, 3 \mathrm{H}), 1.08(\mathrm{~d}, J$ $=6.8 \mathrm{~Hz}, 3 \mathrm{H}), 0.98(\mathrm{t}, J=8.0 \mathrm{~Hz}, 9 \mathrm{H}), 0.97(\operatorname{app~d}, J=8.0 \mathrm{~Hz}, 1 \mathrm{H}), 0.59-0.76(\mathrm{~m}, 6 \mathrm{H}), 0.32(\mathrm{bdd}, J=$ 1.6, 9.2 Hz, 1H); ${ }^{13} \mathrm{C}$ NMR (100MHz, $\left.\mathrm{CDCl}_{3}\right) \square 211.2,173.7,136.1,134.3,126.0,118.5,108.9,87.5$, $82.2,82.2,82.2,80.7,78.5,77.4,77.2,75.4,69.7,63.9,44.5,40.4,35.2,33.3,30.9,29.2,27.8,27.1,26.9$, 22.3, 19.2, 16.1, 7.1, 5.4; IR (neat) 3310, 2049, 1978, 1732, 1238, $1170 \mathrm{~cm}^{-1}$; HRMS (ES+) $\mathrm{m} / z$ for $\mathrm{C}_{38} \mathrm{H}_{56} \mathrm{FeO}_{9} \mathrm{SiNa}[\mathrm{M}+\mathrm{Na}]^{+}$calcd 763.2941, found 763.2944.

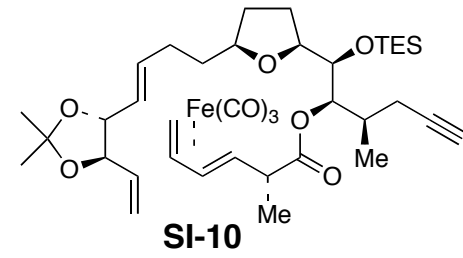

(E)-(R)-2-Methyl-hexa-3,5-dienoic

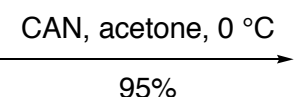

acid

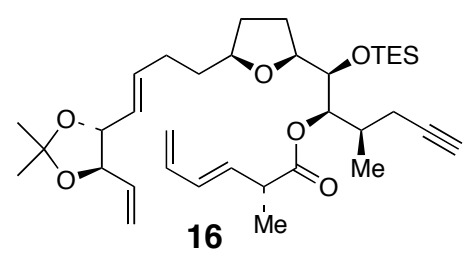

$(1 R, 2 R)-1-((R)-\{(2 S, 5 S)-5-[(E)-4-((4 R, 5 R)-2,2-$

dimethyl-5-vinyl-[1,3] dioxolan-4-yl)-but-3-enyl]-tetrahydro-furan-2-yl\}-triethylsilanyloxy-methyl)-

2-methyl-pent-4-ynyl ester (16) To a $0{ }^{\circ} \mathrm{C}$ solution of SI-10 (45 mg, $\left.0.061 \mathrm{mmol}\right)$ in acetone (1 mL) was added cerium ammonium nitrate (CAN) $(67 \mathrm{mg}, 0.122 \mathrm{mmol})$. The reaction was stirred for $1 \mathrm{~h}$, then quenched with triethylamine $(1 \mathrm{~mL})$ and diluted with sat. aq. $\mathrm{NaHCO}_{3}(30 \mathrm{~mL})$ and $\mathrm{Et}_{2} \mathrm{O}(30 \mathrm{~mL})$. The aqueous phase was extracted with $\mathrm{Et}_{2} \mathrm{O}(20 \mathrm{~mL} \times 3)$. The organic phase was washed with brine, dried over anhydrous $\mathrm{MgSO}_{4}$, filtered and concentrated. The crude product was purified by flash column chromatography to afford $16(35 \mathrm{mg}, 95 \%)$ as a colorless oil: $[\square]^{25}=-1.0^{\circ}\left(c 0.10, \mathrm{CHCl}_{3}\right) ;{ }^{1} \mathrm{H}$ NMR $\left(400 \mathrm{MHz}, \mathrm{CDCl}_{3}\right) \square 6.29(\mathrm{dt}, J=10.0,16.8,1 \mathrm{H}), 6.15(\mathrm{dd}, J=10.4,15.2 \mathrm{~Hz}, 1 \mathrm{H}), 5.72-5.82(\mathrm{~m}, 3 \mathrm{H})$, 5.42 (bdd, $J=1.6,6.0,15.6 \mathrm{~Hz}, 1 \mathrm{H}), 5.32$ (d, $J=16.4 \mathrm{~Hz}, 1 \mathrm{H}), 5.22$ (dd, $J=1.2,10.4 \mathrm{~Hz}, 1 \mathrm{H}), 5.17$ (d, $J$ $=17.6,1 \mathrm{H}), 5.06(\mathrm{~d}, J=10.0 \mathrm{~Hz}, 1 \mathrm{H}), 4.70(\mathrm{dd}, J=2.0,8.8 \mathrm{~Hz}, 1 \mathrm{H}), 4.04($ app q, $J=7.2 \mathrm{~Hz}, 2 \mathrm{H}), 3.71$ (quint., $J=5.6 \mathrm{~Hz}, 1 \mathrm{H}$ ), 3.67 (dd, $J=2.0,7.2 \mathrm{~Hz}, 1 \mathrm{H}$ ), 3.59 (q, $J=6.4 \mathrm{~Hz}, 1 \mathrm{H}$ ), 3.21 (quint., $J=7.2 \mathrm{~Hz}$, $1 \mathrm{H}), 1.98-2.36(\mathrm{~m}, 5 \mathrm{H}), 1.94(\mathrm{t}, J=2.4 \mathrm{~Hz}, 1 \mathrm{H}), 1.74-1.88(\mathrm{~m}, 2 \mathrm{H}), 1.57-1.66(\mathrm{~m}, 1 \mathrm{H}), 1.46-1.56(\mathrm{~m}$, $1 \mathrm{H}), 1.43(\mathrm{~s}, 3 \mathrm{H}), 1.42(\mathrm{~s}, 3 \mathrm{H}), 1.36-1.45(\mathrm{~m}, 2 \mathrm{H}), 1.29(\mathrm{~d}, J=6.8 \mathrm{~Hz}, 3 \mathrm{H}), 1.08(\mathrm{~d}, J=6.4 \mathrm{~Hz}, 3 \mathrm{H}), 0.95$ $(\mathrm{t}, J=6.8 \mathrm{~Hz}, 9 \mathrm{H}), 0.57-0.72(\mathrm{~m}, 6 \mathrm{H}) ;{ }^{13} \mathrm{C} \mathrm{NMR}\left(100 \mathrm{MHz}, \mathrm{CDCl}_{3}\right) \square 173.7,136.3,136.2,134.3,132.5$, 132.3, 125.8, 118.5, 117.0, 108.8, 82.4, 82.2, 82.2, 80.4, 78.4, 77.4, 75.3, 69.6, 42.8, 35.2, 33.3, 30.9, 29.2, 27.0, 26.9, 22.2, 17.0, 16.1, 7.0, 5.3; IR (neat) 3310, 2953, 2876, 1733, 1378, $1239 \mathrm{~cm}^{-1}$; HRMS $(\mathrm{ES}+) \mathrm{m} / z$ for $\mathrm{C}_{35} \mathrm{H}_{56} \mathrm{O}_{6} \mathrm{SiNa}[\mathrm{M}+\mathrm{Na}]^{+}$calcd 623.3744 , found 623.3748 .
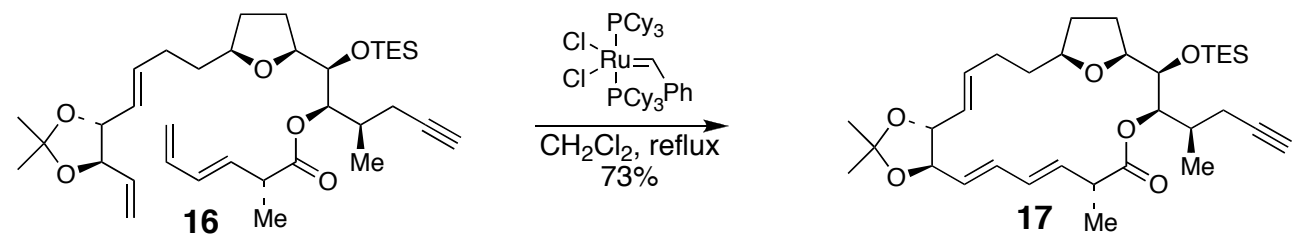
(4E,11E,13E)-(1S,6R,10R,15R,18R,19R,20S)-8,8,15-Trimethyl-18-((R)-1-methyl-but-3ynyl)-19-triethylsilanyloxy-7,9,17,23-tetraoxa-tricyclo[18.2.1.0 $\left.{ }^{6,10}\right]$ tricosa-4,11,13-trien-16-one

To polyene 16 (63 mg, $0.105 \mathrm{mmol})$ in dichloromethane (105 mL) was added Grubbs' first generation catalyst $(17 \mathrm{mg}, 0.021 \mathrm{mmol})$ in dichloromethane $(2 \mathrm{~mL})$. The reaction was fitted with a condenser, refluxed for $12 \mathrm{~h}$ and condensed. The crude product was purified by flash column chromatography to afford 17 (44 mg, 73\%) as a colorless oil. In addition, an inseparable mixture of products thought to arrive by eneyne metathesis $(4 \mathrm{mg}, 10 \%)$ was also isolated. Spectroscopic data for $17:[\square]^{25}{ }_{\mathrm{D}}=-34^{\circ}(c$ 0.21, $\left.\mathrm{CHCl}_{3}\right) ;{ }^{1} \mathrm{H}$ NMR $\left(400 \mathrm{MHz}, \mathrm{CDCl}_{3}\right) \square 6.15-6.26(\mathrm{~m}, 2 \mathrm{H}), 5.72(\mathrm{ddd}, J=3.6,9.6,15.2 \mathrm{~Hz}, 1 \mathrm{H})$, 5.49-5.57 (m, 2H), 5.33 (app dd, $J=8.4,15.6 \mathrm{~Hz}, 1 \mathrm{H}), 4.55$ (app dd, $J=1.6,9.6 \mathrm{~Hz}, 1 \mathrm{H}), 4.02$ (app dt, $J$ $=8.4,26.0 \mathrm{~Hz}, 2 \mathrm{H}), 3.71$ (app dd, $J=1.6,8.4 \mathrm{~Hz}, 1 \mathrm{H}), 3.20-3.35(\mathrm{~m}, 3 \mathrm{H}), 2.19-2.36(\mathrm{~m}, 3 \mathrm{H}), 1.82-2.03$ $(\mathrm{m}, 3 \mathrm{H}), 1.95(\mathrm{t}, J=2.8 \mathrm{~Hz}, 1 \mathrm{H}), 1.62-1.70(\mathrm{~m}, 1 \mathrm{H}), 1.50-1.59(\mathrm{~m}, 1 \mathrm{H}), 1.38-1.49(\mathrm{~m}, 1 \mathrm{H}), 1.43(\mathrm{~s}, 3 \mathrm{H})$, $1.42(\mathrm{~s}, 3 \mathrm{H}), 1.23(\mathrm{~d}, J=6.8 \mathrm{~Hz}, 3 \mathrm{H}), 1.15-1.28(\mathrm{~m}, 2 \mathrm{H}), 1.06(\mathrm{~d}, J=6.4 \mathrm{~Hz}, 3 \mathrm{H}), 0.96(\mathrm{t}, J=7.6 \mathrm{~Hz}$, 9H), 0.57-0.73 (m, 6H); ${ }^{13} \mathrm{C} \mathrm{NMR}\left(100 \mathrm{MHz}, \mathrm{CDCl}_{3}\right) \square 174.2,138.4,135.5,131.3,127.6,125.7,109.0$, 83.0, 82.9, 82.3, 79.9, 78.5, 77.2, 75.1, 69.3, 44.2, 33.2, 32.0, 29.6, 28.6, 27.2, 27.1, 27.0, 22.5, 16.9, 15.6, 7.1, 5.6; IR (neat) 3310, 2950, 2874, 1732, 1378, 1237, 1170, $1053 \mathrm{~cm}^{-1}$; HRMS (ES+) $\mathrm{m} / z$ for $\mathrm{C}_{33} \mathrm{H}_{52} \mathrm{O}_{6} \mathrm{SiNa}[\mathrm{M}+\mathrm{Na}]^{+}$calcd 595.3431, found 595.3442.
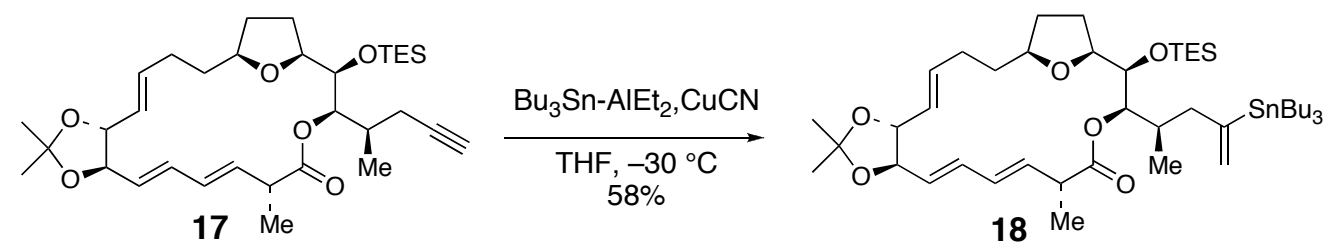

(4E,11E,13E)-(1S,6R,10R,15R,18R,19R,20S)-8,8,15-Trimethyl-18-((R)-1-methyl-3-

tributylstannanyl-but-3-enyl)-19-triethylsilanyloxy-7,9,17,23-tetraoxa-tricyclo[18.2.1.0 $\left.{ }^{6,10}\right]$ tricosa-

4,11,13-trien-16-one (18) To a $0{ }^{\circ} \mathrm{C}$ solution of $i$ - $\mathrm{Pr}_{2} \mathrm{NH}(0.45 \mathrm{~mL}, 3.2 \mathrm{mmol})$ in THF $(3 \mathrm{~mL})$ was added $\mathrm{n}-\mathrm{BuLi}(1.30 \mathrm{~mL}$ of a $2.31 \mathrm{M}$ solution in hexanes, $3.0 \mathrm{mmol})$. The reaction was allowed to stir for $30 \mathrm{~min}$ and then cooled to $-30{ }^{\circ} \mathrm{C}$. To this mixture was added $\mathrm{Bu}_{3} \mathrm{SnH}(0.80 \mathrm{~mL}, 3.0 \mathrm{mmol})$. After $1 \mathrm{~h}, \mathrm{Et}_{2} \mathrm{AlCl}$ $(1.7 \mathrm{~mL}$ of a $1.8 \mathrm{M}$ solution in toluene, $3.0 \mathrm{mmol})$ was added. The reaction was stirred at $-30{ }^{\circ} \mathrm{C}$ for another $1.5 \mathrm{~h}$ and then used immediately in the stannylalumination-protonylysis of 17.

To a $-30{ }^{\circ} \mathrm{C}$ solution of $\mathbf{1 7}(44 \mathrm{mg}, 0.077 \mathrm{mmol})$ in THF $(1 \mathrm{~mL})$ was added $\mathrm{Bu}_{3} \mathrm{Sn}_{-} \mathrm{AlEt}_{2}(1.1 \mathrm{~mL}$ of the $0.41 \mathrm{M}$ solution from above, $0.45 \mathrm{mmol})$, followed by CuCN $(2 \mathrm{mg}, 0.022 \mathrm{mmol})$. The bright orange solution was stirred for $1 \mathrm{~h}$ at $-30{ }^{\circ} \mathrm{C}$, then quenched with sat. aq. $\mathrm{NH}_{4} \mathrm{Cl}(20 \mathrm{~mL})$ and $\mathrm{Et}_{2} \mathrm{O}(20$ $\mathrm{mL}$ ). This mixture was stirred vigorously at room temp for $15 \mathrm{~min}$. The aqueous phase was extracted with $\mathrm{Et}_{2} \mathrm{O}(10 \mathrm{~mL} \times 3)$. The organic phase was washed with brine, dried over anhydrous $\mathrm{MgSO}_{4}$, filtered and concentrated. Purification of the crude product by flash column chromatography afforded 18 (38 mg, $58 \%$ ) as a colorless oil: $[\square]^{25}{ }_{\mathrm{D}}=-34.5^{\circ}\left(\mathrm{c} 0.11, \mathrm{CHCl}_{3}\right) ;{ }^{1} \mathrm{H} \mathrm{NMR}\left(400 \mathrm{MHz}, \mathrm{CDCl}_{3}\right) \square 6.15-6.26(\mathrm{~m}, 2 \mathrm{H})$, 
5.72 (app ddd, $J=3.6,9.6,15.2 \mathrm{~Hz}, 1 \mathrm{H}), 5.63\left(\operatorname{app~t},{ }^{3} J_{\mathrm{Sn}-\mathrm{H}}=70 \mathrm{~Hz}, 1 \mathrm{H}\right), 5.50-5.90(\mathrm{~m}, 2 \mathrm{H}), 5.34(\mathrm{dd}, J=$ $8.8,15.2 \mathrm{~Hz}, 1 \mathrm{H}), 5.14\left(\mathrm{dt}, \mathrm{J}=2.4 \mathrm{~Hz},{ }^{3} J_{\mathrm{Sn}-\mathrm{H}}=31.6 \mathrm{~Hz}, 1 \mathrm{H}\right), 4.50(\mathrm{~d}, J=10.0 \mathrm{~Hz}, 1 \mathrm{H}), 4.02(\operatorname{app~dt}, J=$ 8.8, 24.0 Hz, 2H), 3.75 (d, $J=8.8 \mathrm{~Hz}, 1 \mathrm{H}), 3.15-3.35$ (m, 3H), 2.33 (d, $J=13.2 \mathrm{~Hz}, 2 \mathrm{H}), 1.82-2.06(\mathrm{~m}$, 4H), 1.60-1.70 (m, 1H), 1.40-1.57 (m, 8H), $1.44(\mathrm{~s}, 3 \mathrm{H}), 1.43(\mathrm{~s}, 3 \mathrm{H}), 1.25-1.36(\mathrm{~m}, 7 \mathrm{H}), 1.22(\mathrm{~d}, J=6.8$ $\mathrm{Hz}, 3 \mathrm{H}), 1.18-1.24(\mathrm{~m}, 2 \mathrm{H}), 0.96(\mathrm{t}, J=8.0 \mathrm{~Hz}, 9 \mathrm{H}), 0.93-0.99(\mathrm{~m}, 1 \mathrm{H}), 0.85-0.93(\mathrm{~m}, 14 \mathrm{H}), 0.81(\mathrm{~d}, J=$ $6.4 \mathrm{~Hz}, 3 \mathrm{H}), 0.55-0.72(\mathrm{~m}, 6 \mathrm{H}) ;{ }^{13} \mathrm{C} \mathrm{NMR}\left(100 \mathrm{MHz}, \mathrm{CDCl}_{3}\right) \square 174.2,154.1,138.5,136.0,135.8,131.1$, 127.5, 126.7, 125.7, 109.0, 83.1, 82.4, 80.1, 79.6, 77.2, 75.0, 45.4, 44.4, 33.0, 32.1, 29.7, 29.2, 29.1, 28.5, 27.4, 27.2, 27.1, 16.9, 14.8, 13.7, 9.6, 7.2, 5.7; IR (neat) 2954, 2931, 2873, 1732, 1237, 1170, $1053 \mathrm{~cm}^{-1}$; HRMS (ES+) $m / z$ for $\mathrm{C}_{45} \mathrm{H}_{80} \mathrm{O}_{6} \mathrm{SiSnNa}[\mathrm{M}+\mathrm{Na}]^{+}$calcd 887.4644, found 887.4655.

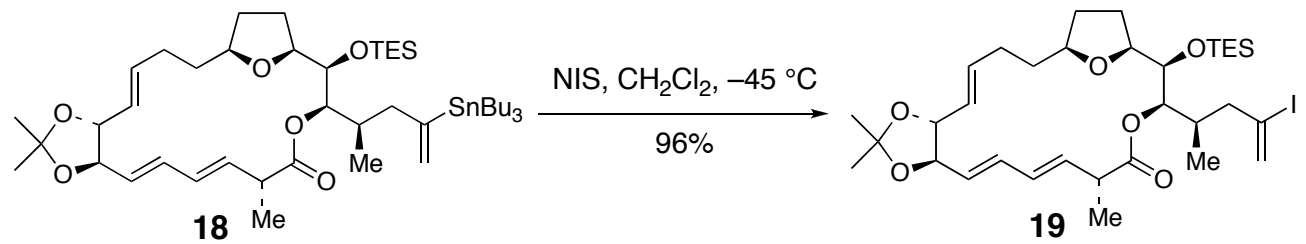

(4E,11E,13E)-(1S,6R,10R,15R,18R,19R,20S)-18-((R)-3-Iodo-1-methyl-but-3-enyl)-8,8,15trimethyl-19-triethylsilanyloxy-7,9,17,23-tetraoxa-tricyclo[18.2.1.0 $\left.{ }^{6,10}\right]$ tricosa-4,11,13-trien-16-one

(19) To a $-45{ }^{\circ} \mathrm{C}$ solution of stannane $18(121 \mathrm{mg}, 0.140 \mathrm{mmol})$ in dichloromethane $(2 \mathrm{~mL})$ was added NIS (38 mg, $0.17 \mathrm{mmol}$ ). The reaction was stirred at $-45^{\circ} \mathrm{C}$ for $2 \mathrm{~h}$ and then quenched with sat. aq. $\mathrm{Na}_{2} \mathrm{~S}_{2} \mathrm{O}_{3}(30 \mathrm{~mL})$ and extracted with $\mathrm{Et}_{2} \mathrm{O}(20 \mathrm{~mL}$ x 3$)$. The organic phase was washed with brine, dried over anhydrous $\mathrm{MgSO}_{4}$, filtered and concentrated. The crude product was purified by flash column chromatography to afford $19(94 \mathrm{mg}, 96 \%)$ as a colorless oil: $[\square]_{\mathrm{D}}^{25}=-63^{\circ}\left(c 0.13, \mathrm{CHCl}_{3}\right) ;{ }^{1} \mathrm{H}$ NMR $\left(400 \mathrm{MHz}, \mathrm{CDCl}_{3}\right) \square 6.15-6.28(\mathrm{~m}, 2 \mathrm{H}), 6.04(\mathrm{~s}, 1 \mathrm{H}), 5.73(\mathrm{~s}, 1 \mathrm{H}), 5.72(\mathrm{ddd}, J=4.0,10.4,14.8 \mathrm{~Hz}, 1 \mathrm{H})$, 5.53 (app dt, $J=9.2,14.4 \mathrm{~Hz}, 2 \mathrm{H}), 5.33(\mathrm{dd}, J=8.8,15.2 \mathrm{~Hz}, 1 \mathrm{H}), 4.56(\mathrm{~d}, J=10.0 \mathrm{~Hz}, 1 \mathrm{H}), 4.02$ (app $\mathrm{dt}, J=8.8,28.4 \mathrm{~Hz}, 2 \mathrm{H}), 3.73(\mathrm{~d}, J=8.8 \mathrm{~Hz}, 1 \mathrm{H}), 3.20-3.37(\mathrm{~m}, 3 \mathrm{H}), 2.28-2.48(\mathrm{~m}, 3 \mathrm{H}), 2.00(\mathrm{dd}, J=$ 10.0, $13.6 \mathrm{~Hz}, 3 \mathrm{H}), 1.82-1.95(\mathrm{~m}, 2 \mathrm{H}), 1.62-1.70(\mathrm{~m}, 1 \mathrm{H}), 1.49-1.58(\mathrm{~m}, 1 \mathrm{H}), 1.43(\mathrm{~s}, 3 \mathrm{H}), 1.42(\mathrm{~s}, 3 \mathrm{H})$, $1.31-1.46(\mathrm{~m}, 2 \mathrm{H}), 1.22(\mathrm{~d}, J=6.8 \mathrm{~Hz}, 3 \mathrm{H}), 1.16-1.20(\mathrm{~m}, 1 \mathrm{H}), 0.98(\mathrm{t}, J=8.0 \mathrm{~Hz}, 9 \mathrm{H}), 0.85(\mathrm{~d}, J=6.4$ $\mathrm{Hz}, 3 \mathrm{H}), 0.56-0.75(\mathrm{~m}, 6 \mathrm{H}) ;{ }^{13} \mathrm{C} \mathrm{NMR}\left(100 \mathrm{MHz}, \mathrm{CDCl}_{3}\right) \square 174.4,138.3,135.9,135.5,131.3,127.7$, 127.1, 125.7, 111.4, 109.0, 83.1, 82.3, 80.0, 78.6, 77.2, 75.0, 48.0, 44.1, 32.7, 32.0, 29.5, 28.5, 27.2, 27.0, 16.9, 14.5, 7.2, 5.7; IR (neat) 2950, 2874, 1731, 1378, 1237, 1170, $1053 \mathrm{~cm}^{-1}$; HRMS (ES+) $\mathrm{m} / z$ for $\mathrm{C}_{33} \mathrm{H}_{53} \mathrm{IO}_{6} \mathrm{SiNa}[\mathrm{M}+\mathrm{Na}]^{+}$calcd 723.2554 , found 723.2559 . 


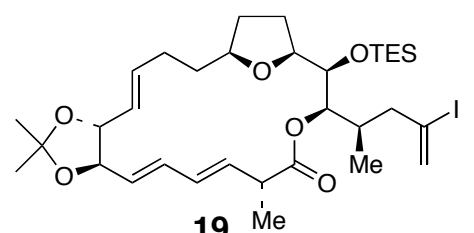

$19 \mathrm{Me}$

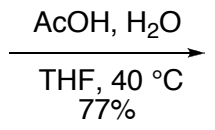

$77 \%$

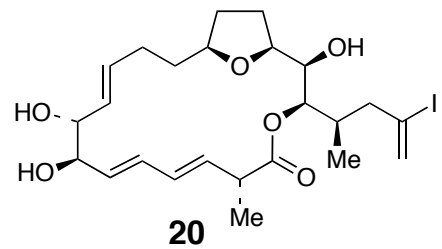

(7E,9E,13E)-(1S,2R,3R,6R,11R,12R,17S)-2,11,12-Trihydroxy-3-((R)-3-iodo-1-methyl-but-3enyl)-6-methyl-4,20-dioxa-bicyclo[15.2.1]icosa-7,9,13-trien-5-one (20). A solution of vinyl iodide 19 $(15 \mathrm{mg}, 0.021 \mathrm{mmol})$ in a mixture of $\mathrm{AcOH}$, THF and water $(4 / 1 / 1)(0.5 \mathrm{~mL})$ was heated to $40{ }^{\circ} \mathrm{C}$ for $6 \mathrm{~h}$. The mixture was then carefully poured into a separatory funnel containing $\mathrm{Et}_{2} \mathrm{O}(20 \mathrm{~mL})$ and sat. aq. $\mathrm{NaHCO}_{3}(40 \mathrm{~mL})$. The aqueous phase was extracted with $\mathrm{Et}_{2} \mathrm{O}(10 \mathrm{~mL}$ x 3). The organic phase was washed with brine, dried over anhydrous $\mathrm{MgSO}_{4}$, filtered and concentrated. The crude product was purified by flash column chromatography to afford $20(9 \mathrm{mg}, 77 \%)$ as a colorless oil: $[\square]_{\mathrm{D}}^{25}=-14.2^{\circ}(\mathrm{c}$ 0.12, $\left.\mathrm{CHCl}_{3}\right) ;{ }^{1} \mathrm{H}$ NMR $\left(400 \mathrm{MHz}, \mathrm{CDCl}_{3}\right) \square 6.10-6.28(\mathrm{~m}, 2 \mathrm{H}), 6.05$ (s, 1H), $5.74(\mathrm{~s}, 1 \mathrm{H}), 5.50-5.69$ (m, $3 \mathrm{H}), 5.26(\mathrm{dd}, J=8.0,15.2 \mathrm{~Hz}, 1 \mathrm{H}), 4.68(\mathrm{~d}, J=9.2 \mathrm{~Hz}, 1 \mathrm{H}), 3.91(\mathrm{app} \mathrm{dt}, J=8.8,28.8 \mathrm{~Hz}, 2 \mathrm{H}), 3.68-$ $3.74(\mathrm{~m}, 1 \mathrm{H}), 3.55$ (app q, $J=7.6 \mathrm{~Hz}, 1 \mathrm{H}), 3.36-3.44(\mathrm{~m}, 1 \mathrm{H}), 3.22-3.31(\mathrm{~m}, 1 \mathrm{H}), 3.35-2.57$ (m, 4H), 2.23-2.31 (m, 1H), $2.05(\mathrm{dd}, J=10.0,14.0 \mathrm{~Hz}, 1 \mathrm{H}), 1.72-1.93(\mathrm{~m}, 3 \mathrm{H}), 1.29-1.62(\mathrm{~m}, 5 \mathrm{H}), 1.25(\mathrm{~d}, J=$ $6.8 \mathrm{~Hz}, 3 \mathrm{H}), 0.93(\mathrm{~d}, J=6.8 \mathrm{~Hz}, 3 \mathrm{H}) ;{ }^{13} \mathrm{C} \mathrm{NMR}\left(100 \mathrm{MHz}, \mathrm{CDCl}_{3}\right) \square 174.4,135.0,134.9,134.1,131.5$, 129.5, 127.3, 110.7, 79.8, 78.1, 77.6, 77.2, 77.1, 76.6, 73.3, 48.4, 44.0, 33.2, 32.5, 29.9, 29.0, 27.1, 17.5, 14.7; IR (neat) 3428, 2932, 2873, 1729, 1167, $990 \mathrm{~cm}^{-1}$; HRMS (ES+) $\mathrm{m} / z$ for $\mathrm{C}_{24} \mathrm{H}_{35} \mathrm{IO}_{6} \mathrm{Na}[\mathrm{M}+\mathrm{Na}]^{+}$ calcd 569.1376, found 569.1369.

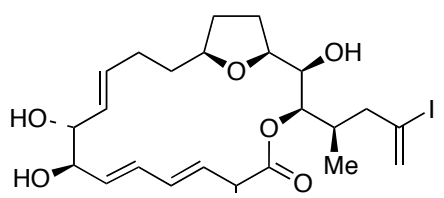

$20 \mathrm{Me}$

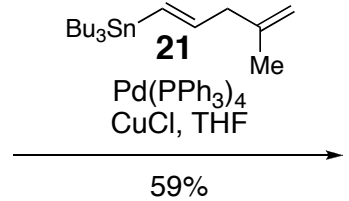

$59 \%$

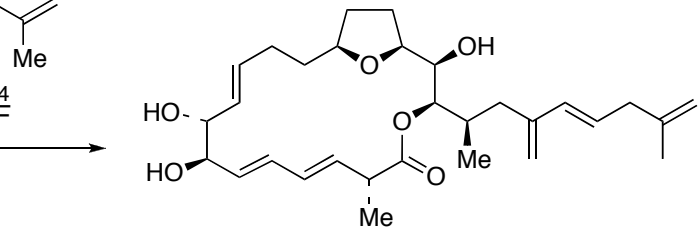

amphidinolide $\mathrm{E}(\mathbf{1})$

Amphidinolide E (1) To a slurry of vinyl iodide 20 (20 mg, $0.037 \mathrm{mmol})$ and $\mathrm{CuCl}(20 \mathrm{mg}$, $0.201 \mathrm{mmol})$ in THF $(0.5 \mathrm{~mL})$ was added vinylstannane $21^{9}$ (68 $\left.\mathrm{mg}, 0.183 \mathrm{mmol}\right)$, followed by $\mathrm{Pd}_{\left(\mathrm{PPh}_{3}\right)_{4}}$ $(8.5 \mathrm{mg}, 0.00732 \mathrm{mmol})$ in THF $(0.5 \mathrm{~mL})$. The reaction was stirred at room temp for $16 \mathrm{~h}$, and then diluted with $\mathrm{Et}_{2} \mathrm{O}(30 \mathrm{~mL})$, filtered through Celite and concentrated. The crude product was purified by flash column chromatography using $10 \%$ methanol/chloroform to afford material that was still contaminated with an organotin impurity. The stannane impurity was removed by hplc purification with $100 \%$ ethyl acetate eluent on a normal phase, Varian Dynamax Microsorb 60-8 Si, 250 x $21.4 \mathrm{~mm}$ column. The retention time for amphidinolide $\mathrm{E}$ was $9.5 \mathrm{~min}$. The flow rate was $18 \mathrm{~mL} / \mathrm{min}$. 
Amphidinolide E was detected using UV absorbtion $(\square=254 \mathrm{~nm}$ and $280 \mathrm{~nm})$ and RI detection. Using the above conditions $10.6 \mathrm{mg}(59 \%)$ of pure amphidinolide $\mathrm{E}$ was isolated: $[\square]_{\mathrm{D}}^{25}=-86^{\circ}\left(\mathrm{c} 0.08, \mathrm{CHCl}_{3}\right)$; ${ }^{1} \mathrm{H}$ NMR (400MHz, $\left.\mathrm{CDCl}_{3}\right) \square 6.10-6.28(\mathrm{~m}, 2 \mathrm{H})(\mathrm{H} 4$ and $\mathrm{H} 5), 6.05$ (d, $\left.J=15.2 \mathrm{~Hz}, 1 \mathrm{H}\right)(\mathrm{H} 22), 5.58-5.75$ $(\mathrm{m}, 3 \mathrm{H})(\mathrm{H} 3, \mathrm{H} 10, \mathrm{H} 23), 5.27$ (dd, $J=7.6,14.4 \mathrm{~Hz}, 1 \mathrm{H})(\mathrm{H} 9), 4.98$ (s, 1H) (H29), 4.87 (s, 1H) (H29), $4.75(\mathrm{~s}, 1 \mathrm{H})(\mathrm{H} 26), 4.71(\mathrm{~s}, 1 \mathrm{H})(\mathrm{H} 26), 4.66(\mathrm{~d}, J=9.2 \mathrm{~Hz}, 1 \mathrm{H})(\mathrm{H} 18), 3.95$ (t, $J=8.4 \mathrm{~Hz}, 1 \mathrm{H})(\mathrm{H} 8), 3.89$ $(\mathrm{t}, J=8.8 \mathrm{~Hz}, 1 \mathrm{H})(\mathrm{H} 7), 3.68-3.74(\mathrm{~m}, 1 \mathrm{H})(\mathrm{H} 17), 3.52-3.60(\mathrm{~m}, 1 \mathrm{H})(\mathrm{H} 16), 3.36-3.45(\mathrm{~m}, 1 \mathrm{H})(\mathrm{H} 13)$, 3.21-3.30 (m, 1H) (H2), 2.71-2.84 (m, 2H) (H24), 2.20-2.45 (m, 6H) (H20a, H19, H11a and -OH x 3), 1.75-1.94 (m, 3H) (H11b, H12a, H20b), 1.72 (s, 3H) (H27), 1.51-1.68 (m, 1H) (H15a, overlapping w/ water), 1.21-1.51 (m, 4H) (H12b, H14a, H14b, H15b), 1.25 (d, $J=6.8 \mathrm{~Hz}, 3 \mathrm{H})(\mathrm{H} 30), 0.92$ (d, $J=6.8 \mathrm{~Hz}$, $3 \mathrm{H})(\mathrm{H} 29) ;{ }^{13} \mathrm{C}$ NMR $\left(100 \mathrm{MHz}, \mathrm{CDCl}_{3}\right) \square 174.4,144.4,144.0,135.1,135.0,134.1,133.3,131.4,131.4$, 129.4, 127.9, 115.7, 110.7, 79.9, 78.3, 78.0, 77.6, 76.7 (overlapping w/ chloroform), 73.2, 44.1, 41.2, 36.0, 32.6, 32.3, 29.9, 28.9, 27.1, 22.5, 17.5, 15.3; IR (neat) 3439, 2929, 1731, 1454, 1168, $990 \mathrm{~cm}^{-1}$; HRMS (ES+) $m / z$ for $\mathrm{C}_{30} \mathrm{H}_{44} \mathrm{O}_{6} \mathrm{Na}[\mathrm{M}+\mathrm{Na}]^{+}$calcd 523.3036, found 523.3038. 


\section{Comparison of ${ }^{1} \mathrm{H}$ NMR Data for Synthetic and Natural Amphidinolide E}

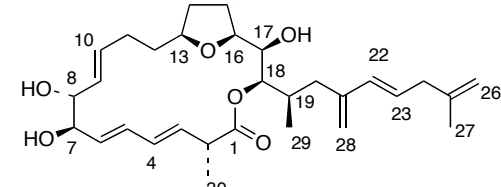

\begin{tabular}{|c|c|c|}
\hline Position & Natural (Kobayashi, 600 MHz) ${ }^{10}$ & Synthetic (Roush, 400 MHz) \\
\hline 1 & ---- & ---- \\
\hline 2 & $3.26(1 \mathrm{H}, \mathrm{dq}, \mathrm{J}=10.0,6.8 \mathrm{~Hz})$ & $3.26(1 \mathrm{H}, \mathrm{m})$ \\
\hline 3 & $5.59(1 \mathrm{H}, \mathrm{dd}, \mathrm{J}=14.0,10.0)$ & $5.59(1 \mathrm{H}, \mathrm{m}) H 3, H 10 \& H 23$ overlap \\
\hline 4 & $6.20(1 \mathrm{H}, \mathrm{dd}, \mathrm{J}=14.0,10.6)$ & $6.20(1 \mathrm{H}, \mathrm{m}) \mathrm{H} 4$ and $\mathrm{H} 5$ overlap \\
\hline 5 & $6.16(1 \mathrm{H}, \mathrm{dd}, \mathrm{J}=14.5,10.6)$ & $6.16(1 \mathrm{H}, \mathrm{m}) \mathrm{H} 4$ and H5 overlap \\
\hline 6 & $5.53(1 \mathrm{H}, \mathrm{dd}, \mathrm{J}=14.5,8.5)$ & $5.53(1 \mathrm{H}, \mathrm{dd}, \mathrm{J}=14.8,8.8)$ \\
\hline 7 & $3.88(1 \mathrm{H}, \mathrm{t}, \mathrm{J}=8.5)$ & $3.89(1 \mathrm{H}, \mathrm{t}, \mathrm{J}=8.8)$ \\
\hline 8 & $3.95(1 \mathrm{H}, \mathrm{t}, \mathrm{J}=8.5)$ & $3.95(1 \mathrm{H}, \mathrm{t}, \mathrm{J}=8.4)$ \\
\hline 9 & $5.27(1 \mathrm{H}, \mathrm{dd}, \mathrm{J}=15.6,8.5)$ & $5.27(1 \mathrm{H}, \mathrm{dd}, \mathrm{J}=14.4,7.6)$ \\
\hline 10 & $5.64(1 \mathrm{H}, \mathrm{m})$ & $5.64(1 \mathrm{H}, \mathrm{m}) \mathrm{H} 3, \mathrm{H} 10 \& \mathrm{H} 23$ overlap \\
\hline $11 \mathrm{a}$ & $2.23(1 \mathrm{H}, \mathrm{m})$ & $2.25(1 \mathrm{H}, \mathrm{m}) \mathrm{H1} 1 \mathrm{a} \& \mathrm{H19}$ overlap \\
\hline $11 \mathrm{~b}$ & $1.82(1 \mathrm{H}, \mathrm{m})$ & $1.82(1 \mathrm{H}, \mathrm{m})$ \\
\hline $12 \mathrm{a}$ & $1.76(1 \mathrm{H}, \mathrm{m})$ & $1.76(1 \mathrm{H}, \mathrm{m})$ \\
\hline $12 \mathrm{~b}$ & $1.48(1 \mathrm{H}, \mathrm{m})$ & $1.48(1 \mathrm{H}, \mathrm{m})$ \\
\hline 13 & $3.41(1 \mathrm{H}, \mathrm{m})$ & $3.40(1 \mathrm{H}, \mathrm{m})$ \\
\hline $14 \mathrm{a}$ & $1.40(1 \mathrm{H}, \mathrm{m})$ & $1.40(1 \mathrm{H}, \mathrm{m})$ \\
\hline $14 \mathrm{~b}$ & $1.25(1 \mathrm{H}, \mathrm{m})$ & $1.25(1 \mathrm{H}, \mathrm{m})$ \\
\hline $15 \mathrm{a}$ & $1.58(1 \mathrm{H}, \mathrm{m})$ & $1.58(1 \mathrm{H}, \mathrm{m})$ overlapping $w /$ water \\
\hline $15 \mathrm{~b}$ & $1.33(1 \mathrm{H}, \mathrm{m})$ & $1.33(1 \mathrm{H}, \mathrm{m})$ \\
\hline 16 & $3.56(1 \mathrm{H}, \mathrm{dt}, \mathrm{J}=7.5,7.1)$ & $3.56(1 \mathrm{H}, \mathrm{m})$ \\
\hline 17 & $3.72(1 \mathrm{H}, \mathrm{dt}, \mathrm{J}=7.5,4.5)$ & $3.72(1 \mathrm{H}, \mathrm{m})$ \\
\hline 18 & $4.66(1 \mathrm{H}, \mathrm{d}, \mathrm{J}=8.3)$ & $4.66(1 \mathrm{H}, \mathrm{d}, \mathrm{J}=9.2)$ \\
\hline 19 & $2.25(1 \mathrm{H}, \mathrm{m})$ & $2.26(1 \mathrm{H}, \mathrm{m}) \mathrm{H1} 1 \mathrm{a} \& \mathrm{H} 19$ overlap \\
\hline $20 \mathrm{a}$ & $2.40(1 \mathrm{H}, \mathrm{d}, \mathrm{J}=13.4)$ & $2.40(1 \mathrm{H}, \mathrm{d}, \mathrm{J}=14.0)$ \\
\hline $20 \mathrm{~b}$ & $1.79(1 \mathrm{H}, \mathrm{m})$ & $1.79(1 \mathrm{H}, \mathrm{m})$ \\
\hline 21 & ---- & ---- \\
\hline 22 & $6.05(1 \mathrm{H}, \mathrm{d}, \mathrm{J}=15.9)$ & $6.05(1 \mathrm{H}, \mathrm{d}, \mathrm{J}=15.2)$ \\
\hline 23 & $5.71(1 \mathrm{H}, \mathrm{dt}, \mathrm{J}=15.9,6.8)$ & $5.71(1 \mathrm{H}, \mathrm{m}) \mathrm{H3}, \mathrm{H1O} \& \mathrm{H} 23$ overlap \\
\hline 24 & $2.78(2 \mathrm{H}, \mathrm{br} \mathrm{d}, \mathrm{J}=6.8)$ & $2.78(2 \mathrm{H}, \mathrm{m})$ \\
\hline 25 & ---- & ---- \\
\hline $26 \mathrm{a}$ & $4.75(1 \mathrm{H}, \mathrm{s})$ & $4.75(1 \mathrm{H}, \mathrm{s})$ \\
\hline $26 \mathrm{~b}$ & $4.71(1 \mathrm{H}, \mathrm{s})$ & $4.71(1 \mathrm{H}, \mathrm{s})$ \\
\hline 27 & $1.72(3 \mathrm{H}, \mathrm{s})$ & $1.72(3 \mathrm{H}, \mathrm{s})$ \\
\hline $28 \mathrm{a}$ & $4.98(1 \mathrm{H}, \mathrm{s})$ & $4.98(1 \mathrm{H}, \mathrm{s})$ \\
\hline $28 \mathrm{~b}$ & $4.87(1 \mathrm{H}, \mathrm{s})$ & $4.87(1 \mathrm{H}, \mathrm{s})$ \\
\hline 29 & $0.92(3 \mathrm{H}, \mathrm{d}, \mathrm{J}=6.6)$ & $0.92(3 \mathrm{H}, \mathrm{d}, \mathrm{J}=6.8)$ \\
\hline 30 & $1.25(3 \mathrm{H}, \mathrm{d}, \mathrm{J}=6.8)$ & $1.25(3 \mathrm{H}, \mathrm{d}, \mathrm{J}=6.8)$ \\
\hline
\end{tabular}


Comparison of ${ }^{13} \mathrm{C}$ NMR Data for Synthetic and Natural Amphidinolide E

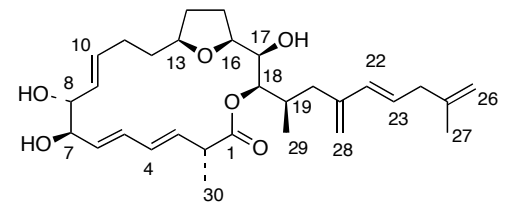

\begin{tabular}{|c|c|c|}
\hline Position & Natural (Kobayashi) & Synthetic (Roush) \\
\hline 1 & $174.42 \mathrm{ppm}$ & 174.4 \\
\hline 2 & 44.06 & 44.1 \\
\hline 3 & 135.14 & 135.1 \\
\hline 4 & 134.93 & 135.0 \\
\hline 5 & 134.15 & 134.1 \\
\hline 6 & 133.34 & 133.3 \\
\hline 7 & 79.86 & 79.9 \\
\hline 8 & 78.27 & 78.3 \\
\hline 9 & 131.40 & 131.4 \\
\hline 10 & 131.37 & 131.4 \\
\hline 11 & 41.26 & 41.3 \\
\hline 12 & 36.07 & 36.0 \\
\hline 13 & 78.04 & 78.0 \\
\hline 14 & 32.60 & 32.6 \\
\hline 15 & 29.94 & 29.9 \\
\hline 16 & 77.58 & 77.6 \\
\hline 17 & 76.68 & 76.7 under $\mathrm{CDCl}_{3}$ \\
\hline 18 & 73.20 & 73.2 \\
\hline 19 & 32.34 & 32.3 \\
\hline 20 & 28.95 & 29.0 \\
\hline 21 & 144.68 & 144.7 \\
\hline 22 & 129.41 & 129.4 \\
\hline 23 & 127.93 & 127.9 \\
\hline 24 & 27.14 & 27.1 \\
\hline 25 & 144.00 & 144.0 \\
\hline 26 & 115.70 & 115.8 \\
\hline 27 & 22.53 & 22.5 \\
\hline 28 & 110.71 & 110.7 \\
\hline 29 & 17.52 & 17.5 \\
\hline 30 & 15.36 & 15.3 \\
\hline
\end{tabular}


Comparison of ${ }^{1} \mathrm{H}$ NMR Data for (S)-MTPA Mosher Triesters of Amphidinolide E

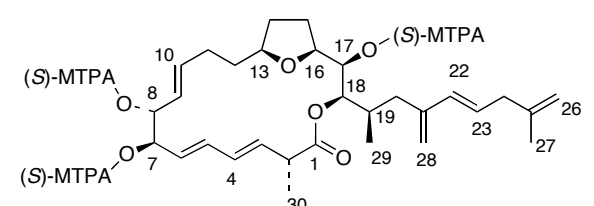

\begin{tabular}{|c|c|c|}
\hline Position & Natural (Kobayashi, 600 MHz) ${ }^{11}$ & Synthetic (Roush, 400 MHz) \\
\hline 1 & ---- & ---- \\
\hline 2 & $3.24(1 \mathrm{H}, \mathrm{m})$ & $3.24(1 \mathrm{H}, \mathrm{m})$ \\
\hline 3 & $5.67(1 \mathrm{H}, \mathrm{m})$ & $5.67(1 \mathrm{H}, \mathrm{m})$ \\
\hline 4 & $6.17(1 \mathrm{H}, \mathrm{dd}, \mathrm{J}=10.4,15.3)$ & $6.17(1 \mathrm{H}, \mathrm{dd}, \mathrm{J}=10.4,14.4)$ \\
\hline 5 & $6.40(1 \mathrm{H}, \mathrm{dd}, \mathrm{J}=10.8,15.3)$ & $6.40(1 \mathrm{H}, \mathrm{dd}, \mathrm{J}=11.2,15.2)$ \\
\hline 6 & $5.39(1 \mathrm{H}, \mathrm{dd}, \mathrm{J}=9.3,15.3)$ & $5.39(1 \mathrm{H}, \mathrm{m})$ \\
\hline 7 & $5.60(1 \mathrm{H}, \mathrm{brt}, \mathrm{J}=9.3)$ & $5.60(1 \mathrm{H}, \mathrm{m})$ \\
\hline 8 & $5.65(1 \mathrm{H}, \mathrm{m})$ & $5.65(1 \mathrm{H}, \mathrm{m})$ \\
\hline 9 & $5.21(1 \mathrm{H}, \mathrm{dd}, \mathrm{J}=7.4,15.6)$ & $5.21(1 \mathrm{H}, \mathrm{dd}, \mathrm{J}=7.2,15.6)$ \\
\hline 10 & $5.75(1 \mathrm{H}, \mathrm{dt}, \mathrm{J}=15.6,7.1)$ & $5.75(1 \mathrm{H}, \mathrm{m})$ \\
\hline $11 \mathrm{a}$ & $2.28(1 \mathrm{H}, \mathrm{m})$ & $2.26(1 \mathrm{H}, \mathrm{m})$ \\
\hline $11 \mathrm{~b}$ & $2.00(1 \mathrm{H}, \mathrm{m})$ & $2.01(1 \mathrm{H}, \mathrm{m})$ \\
\hline $12 \mathrm{a}$ & $1.56(1 \mathrm{H}, \mathrm{m})$ & $1.56(1 \mathrm{H}, \mathrm{m})$ \\
\hline $12 \mathrm{~b}$ & $1.72(1 \mathrm{H}, \mathrm{m})$ & $1.72(1 \mathrm{H}, \mathrm{m})$ \\
\hline 13 & $3.31(1 \mathrm{H}, \mathrm{m})$ & $3.31(1 \mathrm{H}, \mathrm{m})$ \\
\hline $14 \mathrm{a}$ & $1.35(1 \mathrm{H}, \mathrm{m})$ & $1.35(1 \mathrm{H}, \mathrm{m})$ \\
\hline $14 \mathrm{~b}$ & $1.79(1 \mathrm{H}, \mathrm{m})$ & $1.79(1 \mathrm{H}, \mathrm{m})$ \\
\hline $15 \mathrm{a}$ & $1.45(1 \mathrm{H}, \mathrm{m})$ & $1.45(1 \mathrm{H}, \mathrm{m})$ \\
\hline $15 b$ & $1.67(1 \mathrm{H}, \mathrm{m})$ & $1.67(1 \mathrm{H}, \mathrm{m})$ \\
\hline 16 & $3.64(1 \mathrm{H}, \mathrm{dt}, \mathrm{J}=6.7,9.3)$ & $3.64(1 \mathrm{H}, \mathrm{m})$ \\
\hline 17 & $5.38(1 \mathrm{H}, \mathrm{d}, \mathrm{J}=9.3)$ & $5.38(1 \mathrm{H}, \mathrm{m})$ \\
\hline 18 & $4.78(1 \mathrm{H}, \mathrm{d}, \mathrm{J}=10.4)$ & $4.78(1 \mathrm{H}, \mathrm{d}, \mathrm{J}=9.6)$ \\
\hline 19 & $1.81(1 \mathrm{H}, \mathrm{m})$ & $1.81(1 \mathrm{H}, \mathrm{m})$ \\
\hline $20 \mathrm{a}$ & $1.74(1 \mathrm{H}, \mathrm{m})$ & $1.74(1 \mathrm{H}, \mathrm{m})$ \\
\hline $20 \mathrm{~b}$ & $2.25(1 \mathrm{H}, \mathrm{m})$ & $2.25(1 \mathrm{H}, \mathrm{m})$ \\
\hline 21 & ---- & ---- \\
\hline 22 & $5.96(1 \mathrm{H}, \mathrm{d}, \mathrm{J}=16.0)$ & $5.96(1 \mathrm{H}, \mathrm{d}, \mathrm{J}=15.2)$ \\
\hline 23 & $5.54(1 \mathrm{H}, \mathrm{dt}, \mathrm{J}=16.0,7.1)$ & $5.54(1 \mathrm{H}, \mathrm{m})$ \\
\hline 24 & $2.71(2 \mathrm{H}$, brt, $\mathrm{J}=7.1)$ & $2.72(2 \mathrm{H}, \mathrm{bs})$ \\
\hline 25 & ---- & --- \\
\hline $26 \mathrm{a}$ & $4.67(1 \mathrm{H}, \mathrm{brs})$ & $4.67(1 \mathrm{H}, \mathrm{brs})$ \\
\hline $26 b$ & $4.74(1 \mathrm{H}, \mathrm{brs})$ & $4.74(1 \mathrm{H}, \mathrm{brs})$ \\
\hline 27 & $1.70(3 \mathrm{H}, \mathrm{s})$ & $1.70(3 \mathrm{H}, \mathrm{s})$ \\
\hline $28 \mathrm{a}$ & $4.72(1 \mathrm{H}, \mathrm{brs})$ & $4.72(1 \mathrm{H}, \mathrm{brs})$ \\
\hline $28 \mathrm{~b}$ & $4.93(1 \mathrm{H}, \mathrm{brs})$ & $4.93(1 \mathrm{H}, \mathrm{brs})$ \\
\hline 29 & $0.86(3 \mathrm{H}, \mathrm{d}, \mathrm{J}=6.7)$ & $0.86(3 \mathrm{H}, \mathrm{d}, \mathrm{J}=6.4)$ \\
\hline 30 & $1.25(3 \mathrm{H}, \mathrm{d}, \mathrm{J}=6.7)$ & $1.25(3 \mathrm{H}, \mathrm{d}, \mathrm{J}=6.7)$ \\
\hline OMe (3x) & $3.34(3 \mathrm{H}, \mathrm{s}), 3.39(3 \mathrm{H}, \mathrm{s}), 3.56(3 \mathrm{H}, \mathrm{s})$ & $3.35(3 \mathrm{H}, \mathrm{s}), 3.39(3 \mathrm{H}, \mathrm{s}), 3.58(3 \mathrm{H}, \mathrm{s})$ \\
\hline Ph groups & $7.31-7.47(14 \mathrm{H}, \mathrm{m})$ & $7.30-7.47(14 \mathrm{H}, \mathrm{m})$ \\
\hline Ph groups & $7.64(1 \mathrm{H}, \mathrm{d}, \mathrm{J}=7.8)$ & $7.64(1 \mathrm{H}, \mathrm{d}, \mathrm{J}=7.6)$ \\
\hline
\end{tabular}


Comparison of ${ }^{1} \mathrm{H}$ NMR Data for (R)-MTPA Mosher Triesters of Amphidinolide E

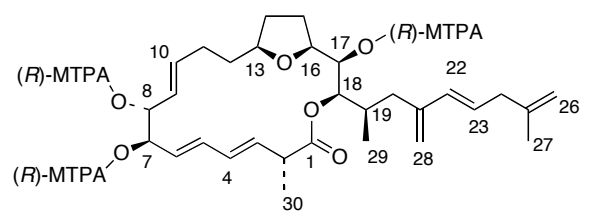

\begin{tabular}{|c|c|c|}
\hline Position & ${\text { Natural (Kobayashi, } 600 \mathrm{MHz})^{11}}$ & Synthetic (Roush, 400 MHz) \\
\hline 1 & ---- & ---- \\
\hline 2 & $3.26(1 \mathrm{H}, \mathrm{m})$ & $3.26(1 \mathrm{H}, \mathrm{m})$ \\
\hline 3 & $5.64(1 \mathrm{H}, \mathrm{m})$ & $5.64(1 \mathrm{H}, \mathrm{m})$ \\
\hline 4 & $6.15(1 \mathrm{H}, \mathrm{dd}, \mathrm{J}=10.8,15.3)$ & $6.15(1 \mathrm{H}, \mathrm{dd}, \mathrm{J}=10.4,15.2)$ \\
\hline 5 & $6.35(1 \mathrm{H}, \mathrm{dd}, \mathrm{J}=10.4,15.3)$ & $6.36(1 \mathrm{H}, \mathrm{dd}, \mathrm{J}=10.8,14.8)$ \\
\hline 6 & $5.28(1 \mathrm{H}, \mathrm{dd}, \mathrm{J}=9.3,15.3)$ & $5.28(1 \mathrm{H}, \mathrm{dd}, \mathrm{J}=8.8,14.8)$ \\
\hline 7 & $5.52(1 \mathrm{H}$, brt, $\mathrm{J}=9.3)$ & $5.52(1 \mathrm{H}$, brt, $\mathrm{J}=9.2)$ \\
\hline 8 & $5.58(1 \mathrm{H}, \mathrm{m})$ & $5.58(1 \mathrm{H}, \mathrm{m})$ \\
\hline 9 & $5.05(1 \mathrm{H}, \mathrm{dd}, \mathrm{J}=7.1,15.6)$ & $5.05(1 \mathrm{H}, \mathrm{dd}, \mathrm{J}=6.4,15.6)$ \\
\hline 10 & $5.45(1 \mathrm{H}, \mathrm{dt}, \mathrm{J}=15.6,7.1)$ & $5.45(1 \mathrm{H}, \mathrm{m})$ \\
\hline $11 \mathrm{a}$ & $1.82(1 \mathrm{H}, \mathrm{m})$ & $1.82(1 \mathrm{H}, \mathrm{m})$ \\
\hline $11 \mathrm{~b}$ & $2.09(1 \mathrm{H}, \mathrm{m})$ & $2.09(1 \mathrm{H}, \mathrm{m})$ \\
\hline $12 \mathrm{a}$ & $1.41(1 \mathrm{H}, \mathrm{m})$ & $1.41(1 \mathrm{H}, \mathrm{m})$ \\
\hline $12 \mathrm{~b}$ & $1.58(1 \mathrm{H}, \mathrm{m})$ & $1.58(1 \mathrm{H}, \mathrm{m})$ \\
\hline 13 & $3.17(1 \mathrm{H}, \mathrm{m})$ & $3.17(1 \mathrm{H}, \mathrm{m})$ \\
\hline $14 \mathrm{a}$ & $1.29(1 \mathrm{H}, \mathrm{m})$ & $1.29(1 \mathrm{H}, \mathrm{m})$ \\
\hline $14 \mathrm{~b}$ & $1.71(1 \mathrm{H}, \mathrm{m})$ & $1.71(1 \mathrm{H}, \mathrm{m})$ \\
\hline $15 \mathrm{a}$ & $1.41(1 \mathrm{H}, \mathrm{m})$ & $1.41(1 \mathrm{H}, \mathrm{m})$ \\
\hline $15 b$ & $1.63(1 \mathrm{H}, \mathrm{m})$ & $1.63(1 \mathrm{H}, \mathrm{m})$ \\
\hline 16 & $3.46(1 \mathrm{H}, \mathrm{m})$ & $3.46(1 \mathrm{H}, \mathrm{m})$ \\
\hline 17 & $5.36(1 \mathrm{H}, \mathrm{d}, \mathrm{J}=9.3)$ & $5.36(1 \mathrm{H}, \mathrm{d}, \mathrm{J}=9.6)$ \\
\hline 18 & $4.81(1 \mathrm{H}, \mathrm{d}, \mathrm{J}=10.4)$ & $4.81(1 \mathrm{H}, \mathrm{d}, \mathrm{J}=10.4)$ \\
\hline 19 & $2.00(1 \mathrm{H}, \mathrm{m})$ & $2.00(1 \mathrm{H}, \mathrm{m})$ \\
\hline $20 \mathrm{a}$ & $1.80(1 \mathrm{H}, \mathrm{dd}, \mathrm{J}=10.4,13.8)$ & $1.80(1 \mathrm{H}, \mathrm{m})$ \\
\hline $20 \mathrm{~b}$ & $2.33(1 \mathrm{H}, \mathrm{dd}, \mathrm{J}=3.4,13.4)$ & $2.33(1 \mathrm{H}$, app d, $\mathrm{J}=14.4)$ \\
\hline 21 & ---- & --- \\
\hline 22 & $6.03(1 \mathrm{H}, \mathrm{d}, \mathrm{J}=15.6)$ & $6.03(1 \mathrm{H}, \mathrm{d}, \mathrm{J}=16.4)$ \\
\hline 23 & $5.61(1 \mathrm{H}, \mathrm{m})$ & $5.61(1 \mathrm{H}, \mathrm{m})$ \\
\hline 24 & $2.72(2 \mathrm{H}, \mathrm{m})$ & $2.72(2 \mathrm{H}, \mathrm{d}, 7.2)$ \\
\hline 25 & ---- & ---- \\
\hline $26 a$ & $4.67(1 \mathrm{H}, \mathrm{brs})$ & $4.67(1 \mathrm{H}, \mathrm{brs})$ \\
\hline $26 b$ & $4.73(1 \mathrm{H}, \mathrm{brs})$ & $4.73(1 \mathrm{H}, \mathrm{brs})$ \\
\hline 27 & $1.69(3 \mathrm{H}, \mathrm{s})$ & $1.69(3 \mathrm{H}, \mathrm{s})$ \\
\hline $28 \mathrm{a}$ & $4.82(1 \mathrm{H}, \mathrm{s})$ & $4.82(1 \mathrm{H}, \mathrm{s})$ \\
\hline $28 b$ & $4.99(1 \mathrm{H}, \mathrm{brs})$ & $4.98(1 \mathrm{H}, \mathrm{brs})$ \\
\hline 29 & $0.90(3 \mathrm{H}, \mathrm{d}, \mathrm{J}=6.7)$ & $0.90(3 \mathrm{H}, \mathrm{d}, \mathrm{J}=6.8)$ \\
\hline 30 & $1.29(3 \mathrm{H}, \mathrm{d}, \mathrm{J}=6.7)$ & $1.29(3 \mathrm{H}, \mathrm{d}, \mathrm{J}=6.8)$ \\
\hline OMe $(3 x)$ & $3.43(3 \mathrm{H}, \mathrm{s}), 3.46(3 \mathrm{H}, \mathrm{s}), 3.53(3 \mathrm{H}, \mathrm{s})$ & $3.43(3 \mathrm{H}, \mathrm{s}), 3.46(3 \mathrm{H}, \mathrm{s}), 3.56(3 \mathrm{H}, \mathrm{s})$ \\
\hline $\mathrm{Ph}$ groups & $7.31-7.47(14 \mathrm{H}, \mathrm{m})$ & $7.31-7.47(14 \mathrm{H}, \mathrm{m})$ \\
\hline $\mathrm{Ph}$ groups & $7.61(1 \mathrm{H}, \mathrm{d}, \mathrm{J}=7.8)$ & $7.60(1 \mathrm{H}, \mathrm{d}, \mathrm{J}=7.2)$ \\
\hline
\end{tabular}




\section{References}

(1) Otera, J.; Danoh, N.; Nozaki, H., J. Org. Chem. 1991, 56, 5307.

(2) Orita, A.; Sakamoto, K.; Hamada, Y.; Mitsutome, A.; Otera, J., Tetrahedron 1999, 55, 2899.

(3) Orita, A.; Mitsutome, A.; Otera, J., J. Org. Chem. 1998, 63, 2420.

(4) Sarabia, F.; Sanchez-Ruiz, A., J. Org. Chem. 2005, 70, 9514.

(5) Roush, W. R.; Koyama, K.; Curtin, M. L.; Moriarty, K. J., J. Am. Chem. Soc. 1996, 118, 7502.

(6) Roush, W. R.; Grover, P. T., Tetrahedron 1992, 48, 1981.

(7) Takacs, J. M.; Jaber, M. R.; Swanson, B. J.; Mehrman, S. J., Tetrahedron: Asymmetry 1998, 9 , 4313.

(8) Wasicak, J. T.; Craig, R. A.; Henry, R.; Dasgupta, B.; Li, H.; Donaldson, W. A., Tetrahedron 1997, 53, 4185.

(9) Gurjar, M. K.; Mohapatra, S.; Phalgune, U. D.; Puranik, V. G.; Mohapatra, D. K., Tetrahedron Lett. 2004, 45, 7899.

(10) Kobayashi, J.; Ishibashi, M.; Murayama, T.; Takamatsu, M.; Iwamura, M.; Ohizumi, Y.; Sasaki, T., J. Org. Chem. 1990, 55, 3421.

(11) Kubota, T.; Tsuda, M.; Kobayashi, J. i., J. Org. Chem. 2002, 67, 1651. 